\title{
Does Pay Activism Pay Off for Shareholders? Shareholder Democracy and its Discontents
}

\author{
Sudipto Dasgupta \\ Department of Accounting and Finance \\ Lancaster University \\ Thomas H. Noe \\ Saïd Business School and Balliol College \\ University of Oxford
}

This version: May 2017

\begin{abstract}
Typically, shareholders are not sure whether boards act in their interest, or have been captured by management. They are also less well informed than boards about firm investment opportunities and operating conditions. We develop a model, consistent with these observations, in which discretionary compensation payments to managers might increase firm value or might simply enrich managers at the expense of shareholders. After observing the board's compensation and investment policies, shareholders update the probability that the board is captured using Bayes rule. Shareholders are "outraged" if this updated probability is sufficiently large. Outrage is costly for the board. Shareholder democracy, by enabling outrage to constrain board actions, typically lowers firm value relative either to governance regimes that insulate boards from shareholder outrage, or regimes that ban discretionary compensation altogether.
\end{abstract}

JEL Classification Codes: G20, G34;

Keywords: governance, shareholder activism, executive compensation, discretionary pay, charter amendments

This paper is based on an earlier paper entitled "Shareholder democracy and its discontents: Outrage, captured boards, and the veil of ignorance." We would like to thank our many perceptive readers for comments on this earlier paper which helped us reformulate our basic insights into a new and more parsimonious modeling framework. In particular, we thank the Editor, the Associate Editor, two anonymous referees, Naveen Khanna (AFA discussant), Rajesh Aggarwal, Bhagwan Chowdhry, Xiuwen Liu, Ernst Maug, Rik Sen, Elu von Thadden, Sheridan Titman, participants in the CAF Summer Research Conference at the Indian School of Business, the Oxford finance lunch workshop, and seminar participants at the University of Amsterdam, Ben-Gurion University, Imperial College, University of Leicester, University of Mannheim, University of Minnesota, Tel Aviv University, the University of Texas at Dallas, and the Higher School of Economics-Moscow. The usual disclaimer applies. 


\section{Introduction}

Shareholder influence on the level and structure of compensation of company executives is now more important than ever before. Moreover, a significant driver of this increased influence is public policy. For example, the Dodd-Frank Act in the U.S. gives shareholders in public companies "Say-on-pay," that is, the right to cast non-binding votes each year on executive pay packages. Judged from the perspective of this legislation, it appears that the public policy makers believe that firm efficiency will be increased by permitting unbiased, but poorly informed, outside shareholders to evaluate specific corporate decisions and, based on their evaluations, pressure better informed but also possibly biased insiders. However, in analogous situations, public policy does not always apply this logic. Judges, for example, act as agents of citizens by interpreting laws and applying the laws to specific cases. Corrupt judges may act in the interest of favored litigants and defendants rather than citizens. However, this analog of Sayon-pay in the case of the judge/citizen relationship_-judicial recall by popular vote- has not been adopted by the most important jurisdictions, e.g., the U.S federal court system, and, where it has been adopted, it is rarely used.

The argument against judicial recall is based on the idea that the threat of recall itself will distort the judicial decision by inducing judges to make their ruling consistent with the perspectives of poorly informed voters. An analogous argument can be made for corporate boards. Contested shareholder votes on director policies imposes costs on directors. ${ }^{1}$ Shareholder preferences over policies are frequently conditioned on general non-firm specific policy guidelines, e.g., institutional investors voting in accordance with "one size fits all" guidelines of proxy advisory firms. ${ }^{2}$ Given shareholders' limited information, the reliance on guidelines might be rational for them, but not optimal, because of the private and firm-specific information possessed by directors. Subjecting some policy choices of informed, but possibly compromised,

\footnotetext{
${ }^{1}$ Cai et al. (2009) find that "withhold" recommendations by Institutional Shareholder services (ISS), one of the worlds leading proxy advisory firms, leads to significantly lower voting support for directors. While directors typically receive more than 90 percent of votes in uncontested director elections, negative shareholder votes or shareholder activism can impose costs on directors through negative publicity or public embarrassment. Lower votes are associated with meaningful changes in CEO turnover, governance changes, and changes in executive compensation. Fischer et al. (2009) report similar findings. Del Guercio et al. (2008) find that " just vote no" campaigns (led by activist shareholders to have as many votes withheld as possible in director elections) are associated with improved performance and CEO turnover. The authors find that these changes occur when the campaigns focus on broad performance and strategy issues, as opposed to being narrowly focused on corporate governance issues, such as compensation. In a study of non-US firms, Iliev et al. (2015) find that dissent voting is more likely when there is concern for expropriation, and leads to more director turnover.

${ }^{2}$ Several papers show that ISS recommendations are significantly related to shareholder voting outcomes-see, for example, Ertimur et al. (2013) and Larcker et al. (2014). Iliev and Lowry (2015) report that over 25 percent of mutual funds vote on the basis of the recommendations of ISS.
} 
boards to pressure from less well informed outside shareholders generates incentives for these boards to manage their reputation with outsiders by using their private information to manipulate other policy levers. Such manipulations can be costly. In fact, in principal-agent models, where a more informed agent is assessed by a less informed principal, reputation management typically leads to distortionary manipulations (Narayanan, 1985; Stein, 1988).

The main insight of this paper is that, because of distortionary manipulation, the cost of subjecting boards to external evaluation by less well informed outside shareholders can easily outweigh the benefits. Distortionary manipulation is most costly in precisely those circumstances where advocates of shareholder democracy claim it is most needed, i.e., when boards are likely to be management oriented. At the same time, we do identify conditions, which depend on the specific firm characteristics, under which democracy can benefit shareholders. Thus, we predict that imposing mandatory shareholder democratic influence over specific managerial compensation decisions will have decidedly mixed effects on shareholder welfare. Such impositions will produce inferior results to reforms that tune the level of outside shareholders' influence over compensation policy to the specific characteristics of their firms.

Consistent with these observations, the evidence on the wealth effects of shareholder pressure on compensation policy is mixed. Larcker et al. (2014) find that companies that amend their executive compensation plans to avoid a negative recommendation from proxy advisory firms exhibit statistically significant negative stock price returns. Ertimur et al. (2013) find no market reaction to announcements of changes in compensation plans in response to negative recommendations by proxy advisory firms. Cai and Walkling (2011) examine market reactions to the passage of the 2007 Say-on-pay Bill. They document average positive stock price reactions to the passage of the Say-on-pay Bill, but negative stock price reactions in some subsamples. Ferri and Maber (2013) find positive stock price reactions to the announcement of Say-on-pay regulation, especially among firms with "excess pay" and poor performance.

One of the most controversial issues in the pay debate is discretionary pay-payments in excess of base salary not based on explicit performance measures. Discretionary compensation payments are pervasive (De Angelis and Grinstein, 2012). Bebchuk and Fried (2005) argue that management oriented boards use discretionary compensation to enrich managers at the expense of shareholders. In contrast, Inderst and Mueller (2010) and Eisfeldt and Rampini (2008) develop models in which discretionary severance pay is an efficient means to induce managers to reveal private information.

As in Inderst and Mueller (2010) and Eisfeldt and Rampini (2008), we also model dis- 
cretionary compensation grants as revelation mechanisms. However, our focus is not on discretionary compensation per se but rather on the scope of the authority of the board to grant such compensation. We show that ex post evaluations of board compensation policy by shareholders can only increase firm value in very special circumstances. Thus, our analysis casts significant doubt on the proposition that mandating increased shareholder influence over board discretionary compensation policy for all firms will increase shareholder welfare.

In our setting, both shareholder oriented boards and manager oriented boards use discretionary compensation, but for very different reasons. While shareholder oriented boards use discretionary compensation to induce managers to reveal information regarding project NPV, manager oriented boards use it to enrich management. Shareholder democracy, by introducing reputational considerations into the board's calculus, leads management oriented boards to deviate even further from shareholder optimal policies in order to manipulate shareholder perceptions.

The key driver of our analysis is the feature that shareholders are less informed than boards and managers along many dimensions. Shareholders are unsure about (a) whether the project's NPV is positive, and (b) whether the project is in the manager's "comfort zone," and (c) whether the board is loyal to shareholders or management.

Shareholders' information about project NPV is restricted to an imprecise signal of project value. Shareholders are also unsure of whether the project is in the manager's comfort zone. If the project is outside the manager's comfort zone, the manager is conflicted, in which case, the manager receives a non-pecuniary "quiet-life" private benefit if the project is rejected. ${ }^{3}$ Finally, shareholders are unsure of board loyalty, i.e., whether the board is fixing compensation policy to maximize shareholder payoffs or to maximize the payoff to the manager. Thus, in contrast to, for example, Song and Thakor (2006), in our model the board actions affect the shareholder assessments of board loyalty rather than ability. We also assume, in contrast to Fisman et al. (2014), these shareholder assessments to be Bayes rational. ${ }^{4}$

As in most models of board/shareholder interaction, boards have better information than

\footnotetext{
${ }^{3}$ Of course, in some sense, shareholder and manager preferences are always in conflict with respect to compensation because managers always prefer higher compensation. Thus, even when the manager is not "conflicted" in our sense, the manager will still prefer to receive compensation in excess of the shareholder optimal level and, thus, through compensation policy, disloyal boards can favor even non-conflicted managers. This is an important feature of our model.

${ }^{4}$ In Levit and Malenko (2016), board members vote for or against management to create a reputation for shareholder or manager friendliness which affects the likelihood of new directorial appointments. A key difference is that in their model, even a reputation for manager friendliness could be rewarded in the labor market due to strategic complementaries in governance. In contrast, our focus is very much on shareholder activism and outrage targeted at manager friendly boards.
} 
shareholders. Obviously, they know to whom they are loyal. They also understand the manager's motivations and thus know whether the manager is conflicted. ${ }^{5}$ In addition, boards have more precise information about the project's NPV than shareholders. However, even the boards' information about project NPV is imperfect. The only agent that has perfect information about board loyalty, managerial preferences, and project NPV, is the manager. Our analysis of shareholder democracy focuses on how boards use their informational advantage over shareholders to manage their reputation for loyalty. In this respect, our model differs from models of board/manager/shareholder interaction where shareholders (Stein, 1988) or managers (Cohn and Rajan, 2013) form reputations.

In our setting, discretionary pay extracts project information from the manager in the following way. When the project NPV is positive, it is in the interest of the shareholders to accept the project. When the manager is conflicted, however, accepting the project will eliminate the manager's quiet-life benefit. Thus, absent any inducement, when the NPV of the project is positive, the conflicted manager has no incentive to report the NPV truthfully. However, when the manager is paid an amount equal to his quiet-life benefit if (and only if) he reports the NPV to be positive, the manager will report truthfully. Such compensation will not increase the welfare of the conflicted manager since it exchanges a non-pecuniary quiet life benefit for a monetary payment of equal value. Thus, in our setting, when the manager is conflicted, discretionary payments are an optimal contracting mechanism. However, if the manager is not conflicted, discretionary payments are not required to induce revelation. For a non-conflicted manager, discretionary payments are a pure windfall that entails no loss of private benefits. Thus, if offered discretionary compensation, non-conflicted managers will readily accept the compensation and the project will thus be accepted regardless of its NPV.

Hence, managers and management oriented boards prefer offering discretionary compensation when managers are not conflicted, while shareholders and shareholder oriented boards prefer offering discretionary compensation when managers are conflicted. A preference for offering discretionary compensation is not per se informative about the orientation of the board. Both manager and shareholder boards prefer offering discretionary compensation under some, albeit very different, conditions.

We compare the shareholder-welfare consequences of ex post shareholder pressure on boards with two types of ex ante charter-based commitment policies: (i) full delegation, which involves

\footnotetext{
${ }^{5}$ Our results depend on the board having superior information to outside shareholders regarding managerial preferences. However, the results are robust to alternative specifications of this advantage. See Online Supplement A for further discussion.
} 
delegating discretionary pay policy to the board and insulating the board from shareholder pressure (e.g., via staggered boards or poison pills), and (ii) charter restriction, which bans discretionary pay completely. Under full delegation, we assume that as long as the board actions do not reveal, with certainty, that the board is disloyal, the board is insulated from shareholder sanction. Under full delegation, when the manager is conflicted, discretionary compensation can be used to elicit the manager's private information about project NPV by both types of board. However, when the manager is not conflicted, discretionary pay is not needed but can be misused by manager oriented boards to enrich management. Under the commitment policy of charter restriction, both the benefits from the appropriate use of discretionary compensation and the costs of its misuse are forgone.

Finally, we consider a non-commitment policy—shareholder democracy. Under shareholder democracy, the firm permits the board to fix compensation/investment policy but exposes the board to ex post shareholder judgment. To model shareholder democracy, we assume that shareholders have rational expectations, and combine their imperfect information regarding firm prospects with their observations of board compensation and investment policy, to assess the board. Shareholder suspicion refers to the shareholders' imperfect posterior assessment that the board is manager oriented. Suspicion affects governance through outrage. Outrage is triggered if board policies are sufficiently suspicious, that is, they induce a sufficiently high posterior probability that the board is manager oriented. Triggering outrage imposes very high costs on the board. We assume that these costs are so high that the board never selects policies that produce outrage. Thus, our model implements the idea of "outrage constraint" on management compensation that has been advanced in the popular, financial economics, and legal literatures. $^{6}$

In our model, discretionary compensation is less beneficial to shareholders when the expected project NPV is low. Thus, discretionary payment grants are most suspicious when the ex post public signal observed by shareholders suggests low project NPV. Under shareholder democracy, the outrage trigger can be violated and discretionary payment can be blocked when the public signal is "low", but discretionary payments might be possible when the signal is "high." Thus democracy, in contrast to the ex ante policies, can support signal contingent blocks on discretionary compensation. If the public signal is informative regarding project NPV, signal contingency might be valuable. By permitting discretionary compensation after the high signal,

\footnotetext{
${ }^{6}$ Clearly, assuming that outrage costs are so large that outrage acts as a constraint on board decision-making is not the only reasonable model of how shareholder assessments affect board behavior. However, we prefer to track the existing literature as closely as possible (Murphy, 2002; Krugman, 2002; Bolton et al., 2006). See Online Supplement B for more discussion of these issues.
} 
when it is more likely to have legitimate use, but blocking it after the low signal, when it is less likely to have such use, it appears that shareholder democracy can increase shareholder welfare relative to both full delegation and charter restriction.

This line of reasoning would be entirely correct if the manager oriented board's behavior were not influenced by the reputational concerns entering the board's decision making by shareholder democracy. However, because of the board's multidimensional information advantage over shareholders, even the Bayes rational shareholders we model find it difficult to interpret board behavior. The probability that discretionary compensation is granted is the "tell" that generates shareholder suspicion. But boards can reduce this probability not only by reducing inappropriate grants to non-conflicted managers but also by reducing appropriate grants to conflicted managers. Shareholders cannot distinguish between these two options. Disloyal boards prefer the second option in order to protect the windfall it produces for managers. This choice, which we term democratic distortion, is costly to shareholders.

Since the distortions due to democracy stem from the actions of the disloyal board, for these costs to be small, the ex ante probability of board disloyalty must be sufficiently small. However, since the main benefit of democracy is to curb the misuse of discretionary pay by disloyal boards, for these gains from democracy to be large, the ex ante probability of board disloyalty must also be sufficiently large. At the same time, the public signal must be sufficiently informative for the value of signal contingency to outweigh the costs of democratic distortion. These requirements together ensure that shareholder democracy only dominates full delegation and charter restrictions for a very narrow range of circumstances Thus, our model suggests that, for a subset of firms, democracy may well increase shareholder value, but for many it will lower it. Hence, our analysis provides no support for the mandatory adoption of policies that favor corporate democracy.

\section{Ex ante governance through charter provisions}

In this section we develop the basic framework of the analysis and analyze the two ex ante commitment policies: full delegation (FD) and charter restriction $(C R)$. In Section 3 we extend the analysis of this section to allow for ex post shareholder intervention through corporate democracy. We postpone the development of the assumptions required only for modeling democracy to that section. 


\subsection{Timing of events}

There are three risk-neutral agents in the model: A professional manager who has no ownership stake in the firm, a board of directors that decides on the investment and compensation policy of the firm, and shareholders who determine the corporate charter and evaluate the board. There are three dates, $t=0, t=1$, and $t=2$. The information and actions available to the agents in the model at these dates are detailed below and graphed in Figure 1.

\subsubsection{Information}

Date $t=0$.

- Board type is determined: There are two types of boards-those that maximize shareholder value and those that maximize the manager's payoff. We call these types the shareholder oriented board (SB) and manager oriented board (MB), respectively. Board type is known by managers and the board, but not known by shareholders. Shareholders' prior assessment of the probability that the board is an MB is represented by $\delta \in(0,1)$.

Date $t=1$.

- The state of the firm is revealed to the board and the manager: The firm is in one of three states: $G$ (Good), $M$ (Medium), and $B$ (Bad). The ex ante probabilities of $G, M$, and $B$ are $\frac{1}{4}, \frac{1}{2}, \frac{1}{4}$.

- The state of the project is revealed to the manager: The net present value of the project (henceforth NPV) can be either positive (state $+\mathrm{NPV}$ ) or negative (state $-\mathrm{NPV}$ ), and project NPV in these states are, respectively, +1 or -1 . In the $G$ state, the probability of a positive NPV project is $\theta \geq \frac{1}{2}$; in the $B$ state, the probability of a negative NPV project is $\theta$; in the $M$ state, the probability of either a positive or negative NPV project is $\frac{1}{2}$.

- The state of the manager is revealed to the board and the manager: The state of the manager equals either $\mathbf{P}$ or NP. In state $\mathbf{P}$, the project is outside the manager's comfort zone and undertaking the project results in the manager losing a quiet-life benefit of $P$, where $0<$ $P<1$. Thus, in state $\mathbf{P}$ there is a potential conflict of interest between the manager and the shareholders with respect to investment policy. In this case, we say that the manager is conflicted. The probability that the manager is conflicted, i.e., the probability that the state of the manager is $\mathbf{P}$, equals $\beta, \beta \in(0,1)$. With probability $1-\beta$, the state of the manager is NP. In the latter case, the manager does not lose any private benefit if the project is accepted, and thus, ignoring the effect on compensation payments, the manager is indifferent to firm investment policy. In this case, we say that the manager is not conflicted. 
- The public signal is observed by the board, the manager, and the shareholders: $x$, a public signal correlated with the state of the firm, is realized. The signal can take two values, $x_{2}$ and $x_{1}$, where $x_{2}>x_{1}$. In state $G$, the high signal, $x_{2}$, is realized with probability 1 ; in state $M$, the high signal, $x_{2}$, and the low signal, $x_{1}$, are realized with equal probability; and in state $B$, the low signal, $x_{1}$, is realized with probability 1 .

Date $t=2$. The project's NPV, either +1 or -1 , is realized.

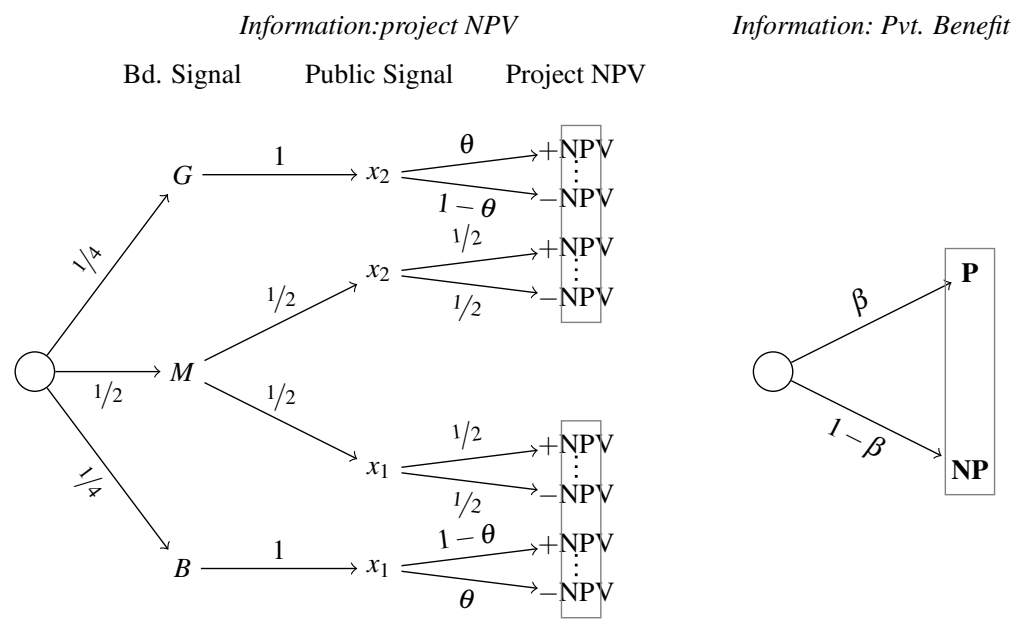

Figure 1: Information structure. The solid rectangles indicate shareholder information sets. The dotted lines indicate board information sets. The manager has complete information.

A few of salient features of our information structure are worthy of note. First, note that the state of the firm induces a probability distribution over the state of the project. Second, because our information structure ensures that the unconditional NPV of the project is zero, and because the state of the firm $B$ and the low public signal $x_{1}$ are both correlated with negative realizations of NPV, the expected NPV of the project is negative conditioned on state of the firm $B$ as well as the low public signal, $x_{1}$. Similarly, the expected NPV of the project is positive conditioned on state of the firm $G$ as well as the high public signal, $x_{2}$. Conditioned on state of the firm $M$, expected project NPV is zero. Regardless of shareholder and board expectations, however, there is always a positive probability that the project's actual NPV is positive or that it is negative. Since the manager knows the actual NPV of the project, the shareholder can always gain from acquiring the manager's private information. Acquiring this information is not problematic when the manager is not conflicted. However, when the manager is conflicted, acquiring this information requires some mechanism for inducing the quiet life manager to reveal positive information about the project and thus risk losing the quiet-life private benefit.

Third, the discretionary compensation problem we model is only interesting under our assumptions that $0<\beta<1$, i.e., when shareholders are uncertain as to whether the manager is 
conflicted or not. If the shareholders know whether the manager is conflicted, they would know the shareholder value maximizing discretionary compensation policy. Given that the shareholders are always loyal to shareholder interests and boards are sometimes disloyal, shareholders would have no incentive to delegate discretionary compensation policy to the board.

Fourth, our information structure provides all agents with some information yet, at the same time, stipulates an information hierarchy. Managers know the most. They have perfect information about their own preferences and the project prospects. Boards occupy an intermediate position. They know the manager's preferences and the state of the firm, which is imperfectly but positively correlated with project prospects. Shareholders observe only a public signal which is imperfectly but positively correlated with the state of the firm, which itself is an imperfect signal for project prospects. Some features of our model are adopted to make the analysis more tractable, and relaxing these would not have any major implications for our results-e.g., it is possible to incorporate imperfect but superior managerial information about project prospects into the analysis. However, the board's intermediate information position is essential for our results. If the board's information set coincided with that of the manager, a shareholder oriented board would never offer discretionary payments to the manager, as such payments increase shareholder welfare only if they elicit information revelation. If the board's information set coincided with that of the shareholders, then shareholders would have no incentive to delegate project selection and compensation decisions to the board, as the possibly disloyal board would have no advantage over shareholders in making such decisions.

\subsubsection{Actions}

All actions occur at date 1 . First the board decides whether or not to offer discretionary compensation (if permitted by charter), or to simply reject or accept the project without offering discretionary compensation. If discretionary compensation is offered, the manager decides whether to accept discretionary compensation tied to the manager's accept/reject decision. After the shareholders observe the accept/reject decision for the project, the public signal, and any discretionary payment to the manager, they form their posterior probability, $\hat{\delta}$, that the board is management oriented. We call this probability shareholder suspicion.

\subsection{Preferences and payoffs}

Board preferences depend on the board's type. An SB maximizes shareholder value, which is the expected project NPV net of the expected discretionary payment to the manager. An MB 
maximizes the payoff to the manager.

The manager's payoff equals expected discretionary compensation plus the expected private benefits. Private benefits depend on whether the manager is conflicted and on whether the project is accepted or rejected. If the manager is not-conflicted, the manager's private benefit is zero regardless of whether the project is accepted or rejected. If the manager is conflicted, the manager receives a private benefit of $P>0$ if the project is rejected and a private benefit of zero if the project is accepted. We refer to $P$ as the manager's "quiet-life benefit." We normalize the manager's reservation payoff to 0 .

Although a large literature in corporate finance is concerned with how managerial preferences generate conflicts of interest between managers and shareholders, there is a surprising lack of consensus on exactly how managerial preferences affect corporate policy. One influential view that has some empirical support is that managers prefer a "quiet life" and eschew projects that are out of their comfort zone (Bertrand and Mullainathan, 2003). This is the perspective we adopt. Another influential notion is that managers prefer "empire building" and thus derive private benefits from investments, irrespective of whether the investments create shareholder value (Williamson, 1964; Jensen, 1993).

Most of the results in this paper do not depend on which of these two assumptions on managerial preferences is appropriate. If the quiet life assumption is appropriate, the managerpreferred action is to reject the project irrespective of its NPV. On the other hand, if the empirebuilding assumption is appropriate, the manager-preferred action is to accept the project irrespective of its NPV. The results in our analysis that do depend on the nature of managerial investment preferences are those that compare behavior after the high and low signals. For such results, we will later discuss the nature of the dependence, and its empirical implications.

\subsection{Discretionary pay}

Discretionary pay delegates the project accept/reject decision to the manager but links the manager's compensation to the manager's decision. One "trivial" discretionary compensation package that is always feasible because it involves no discretionary payments to the manager is the "zero-discretionary pay" policy. Under this policy, the project accept/reject decision is delegated to the manager and the manager receives zero discretionary compensation regardless of the manager's accept/reject decision. To avoid the somewhat awkward locution "zerodiscretionary pay" we describe the policy of offering zero-discretionary pay and letting the manager make the project accept/reject decision simply as "delegating" investment policy to 
the manager, and we restrict the usage of the term "discretionary compensation" to cases where positive payments are offered to the manager.

Absent charter restrictions, in the conflicted state, the manager's information regarding the state of the project can be elicited by means of the following direct mechanism: If the manager reports that the project has negative NPV, then he receives 0 and the project is rejected; if the manager reports that the project has positive NPV, the project is accepted and the manager receives a discretionary payment, $D_{c}$. If $D_{c}=P$, this revelation mechanism will induce the manager to reveal the project NPV truthfully because the value the payment equals the quiet life benefit. Any payment in excess of $P$ enriches managers at the expense of shareholders and will lead the manager to report that the project is positive NPV regardless of his private information signal. No payment smaller than $P$ will elicit revelation of positive NPV investment opportunities. Thus, if the shareholder oriented board pays discretionary compensation, it will always offer $D_{c}=P$ and when the manager accepts this offer, the project will be accepted.

In practice, it may be difficult to formally incorporate a simple direct mechanism such as the one described above as part of a managerial compensation contract, since this would require verifiability of the state of the manager and the manager's report. However, the outcome of the direct mechanism can be implemented by the following indirect mechanism: If and only if the conflicted state is realized, the manager is offered the following compensation package: either accept a discretionary payment of $D_{c}=P$ and accept the project, or reject the project and receive 0 . Under this package, it is incentive compatible for the manager to accept the discretionary compensation and implement the project if the project is positive NPV, and reject the project and the discretionary payment if the project is negative NPV. ${ }^{7}$ Note also that, amongst all discretionary mechanisms that induce revelation, this indirect mechanism is optimal from the shareholder's perspective as it provides a conflicted, and only conflicted, manager with the minimal benefit required to induce revelation, $P$. Other forms of discretionary compensation might also be optimal, e.g., discretionary stock grants, as long as they also provide the conflicted manager with an expected increase in compensation value equal to $P$ conditioned on accepting the project. But such alternative forms of discretionary compensation are never strictly more efficient from the shareholders' perspective.

Of course, the firm need not use a discretionary mechanism at all. Shareholders could ex ante, at date zero, vote to endow the manager with an ownership stake in the firm sufficiently large for the manager to internalize enough of the NPV increase generated by undertaking the

\footnotetext{
${ }^{7}$ We assume the manager has limited liability, and cannot be made to pay $P$ to reject the project.
} 
project. In this scenario, even when the manager is conflicted, the manager would still gain from undertaking positive NPV investments. If firms adopt such ex ante policies, then offering ex post discretionary compensation is never in the interest of the shareholders. In this case, our model and other models of discretionary compensation (e.g., Inderst and Mueller, 2010; Eisfeldt and Rampini, 2008) are moot as they model solutions to an ex post problem that has already been resolved by ex ante commitment. Strictly speaking, the choice between ex ante commitment and ex post discretionary compensation is outside the scope of this paper as we do not model ex ante compensation policy. However, it is easy to see that ex ante commitment is not always optimal-ex ante commitment requires providing the manager with an ownership stake or compensation plan that increases managerial welfare by at least $P$ if the project is undertaken. Thus, the cost of ex ante commitment to shareholders is at least $P$. Ex ante commitment only benefits shareholders when the manager is conflicted, which occurs with probability $\beta$. As $\beta \rightarrow 0$, the benefit of ex ante commitment converges to 0 while its cost, $P$, remains positive. Thus, for $\beta$ sufficiently small, discretionary policies dominate ex ante commitment.

We follow the indirect mechanism interpretation of the discretionary compensation provided above. Thus, when discretionary compensation is offered, the manager chooses whether to accept or reject the project and the discretionary payment is linked to project acceptance. Thus, if the board offers discretionary compensation, or delegates, the manager makes the project accept/reject decision. Otherwise, the board dictates investment and compensation policy. ${ }^{8}$ Absent the incentives generated by reputational concerns introduced later when we model corporate democracy, we assume that the board and manager make efficient choices, i.e., when choosing between alternatives over which they are indifferent, the manager and the MB choose polices that maximize shareholder welfare; similarly, the SB, when choosing over polices over which it is indifferent, chooses policies that maximize managerial welfare.

Calling the indirect mechanism "discretionary compensation" is justified because the compensation proposal is left to the discretion of the board and is not contractually contingent on any realized state. The discretionary payments we model amount to implicit payments for "truth telling" or equivalently, for taking actions that are against the manager's self interest. ${ }^{9}$

\footnotetext{
${ }^{8}$ In some cases, boards have many policies that are effectively equivalent. Policies are equivalent if they produce the same shareholder payoff, the same shareholder suspicion at all shareholder information sets, and the same manager payoff. For example, for any history in which the manager is conflicted, delegating project selection to a conflicted manager is equivalent to dictating rejection. We do not distinguish between equivalent polices. So, for example, when we say the MB ensures project rejection when the manager is conflicted, we are asserting that either the MB delegates investment policy to the manager (leading to rejection because of the manager's quiet-life benefit) or the MB dictates rejection.

${ }^{9}$ Harford (2003), for example, reports that Bank of America directors received a cash bonus of $\$ 300,000$ when Bank of America merged into Nationsbank. The cash bonus was explained as follows: "the purpose also was to
} 
Finally, we assume that, when the manager is conflicted, offering the discretionary pay to elicit project information is better for shareholders than accepting or rejecting the project without offering discretionary pay. Note that, if discretionary pay is used, the shareholders' payoff is $1-P$ if the project is accepted and 0 if it is rejected. In the $B$ (resp. $M$ ) state, expected project NPV is negative (zero). Thus, the shareholders' payoff from dictating investment policy (rejection in state $B$ and either acceptance or rejection in state $M$ ) is zero. For this reason, the gain from using discretionary pay is $(1-\theta)(1-P)-0$ in state $B$ and $\frac{1}{2}(1-P)-0$ in state $M$, both of which are positive. In the $G$ state, the project will be accepted in the absence of discretionary pay, so the gain to shareholders from using discretionary pay is $\theta(1-P)-(\theta-$ $(1-\theta))$. Hence, using the discretionary pay mechanism is strictly optimal in all states if and only if

$$
(1-\theta)-\theta P>0
$$

For the rest of the paper, we assume that condition (1) holds.

\subsection{Governance regimes, firm value and welfare}

Whether boards are able to offer discretionary compensation depends on the corporate charter. We consider two regimes: full delegation (FD) and charter restriction $(C R)$. In the FD regime, the shareholders delegate to the board the task of setting pay and determining investment policy. Under FD, shareholder intervention is triggered if and only if the board undertakes an egregious action. We define egregious board actions as those that are never shareholder value- maximizing in any state of nature.

The FD regime aims to formalize the concept of "director primacy" developed in Bainbridge (2005). Bainbridge and other legal scholars argue for governance policies in which shareholder intervention is encouraged only as a last-resort defense against clearly egregious board behavior. They also assert that the director primacy perspective informed corporate governance practice and corporate law in the U.S. before recent legislative interventions. We assume that the directors are highly averse to intervention and never undertake actions that might provoke intervention, i.e. boards never undertake clearly egregious actions.

In the $\mathrm{CR}$ regime, the shareholders prohibit discretionary compensation payments ex ante through charter provisions. The CR regime is a stylized version of ex ante constitutional control of director behavior. While such restrictions might be the result of shareholder activism, they do involve ex post evaluation of boards by shareholders and thus do not fall within the scope of thank people who had, after all, voted themselves out of a job by approving the merger." 
corporate democracy as defined in this paper.

Note that, as shown in Section 2.3, if a shareholder oriented board offers discretionary compensation, it offers discretionary compensation equal to $P$, and if discretionary compensation is accepted by the manager, and thus paid, the project is always accepted. As a result, any compensation policy under which either discretionary compensation not equal to $P$ is paid, or discretionary compensation is paid and the project is rejected, would identify the board as manager oriented with certainty. Hence, such compensation would violate the egregious action constraint. Thus, when the board offers discretionary compensation, it is constrained to offering the manager a payment of $P$ conditioned on the manager accepting the project.

\subsubsection{Board actions when the manager is conflicted}

FD regime: We first consider shareholder payoffs when the manager is conflicted. Under the FD regime, both the SB and the MB offer discretionary compensation. If the manager accepts it, the project is also accepted. The SB's policy strictly increases shareholder payoff (relative to not offering discretionary pay or dictating investment policy), as reflected in condition (1). The MB's policy makes the manager as well off as from rejecting the project, and better off than he would be if the board dictated project acceptance. Under both the SB and MB, the project will be accepted if and only if it has a positive NPV, in which case, a discretionary payment, $P$, is paid to the manager. The shareholder payoffs resulting from the board's policies are provided in Table 1.

CR regime: Under the $\mathrm{CR}$ regime, the $\mathrm{SB}$ cannot extract the manager's private information about project NPV using discretionary compensation, so it will strictly prefer to dictate project acceptance when the state is $G$ and thus the expected NPV is positive. In state $B$, the project has negative expected NPV, so the SB is indifferent between dictating rejection and delegating investment policy (in which case, the manager, to preserve the quiet-life benefit, will reject the project). In in state $M$, the project has zero expected NPV, so the SB is indifferent between dictating acceptance, rejection, or delegation. The MB under the CR regime cannot offer discretionary compensation. Thus, it can only affect the manager's welfare through affecting project selection. Because of the quiet-life benefit to the manager from rejecting the project, the manager's welfare is maximized through project rejection. The project will be rejected if either the board dictates rejection or delegates investment policy to the manager. In either case, the NPV of the project is lost and shareholders receive a payoff of zero. The shareholder payoffs 


\begin{tabular}{|c|c|c|c|c|}
\hline \multirow[b]{4}{*}{ Regime } & \multirow[b]{4}{*}{ State } & \multirow[b]{4}{*}{ Prob. } & \multicolumn{2}{|c|}{ Board Orientation } \\
\hline & & & MB & SB \\
\hline & & & \multicolumn{2}{|c|}{ Prob. } \\
\hline & & & $\delta$ & $1-\delta$ \\
\hline \multirow{3}{*}{ FD } & $\mathrm{G} \& \mathbf{P}$ & $\beta / 4$ & $\theta(1-P)$ & $\theta(1-P)$ \\
\hline & $\mathbf{M} \& \mathbf{P}$ & $\beta / 2$ & $\frac{1}{2}(1-P)$ & $\frac{1}{2}(1-P)$ \\
\hline & B \& $\mathbf{P}$ & $\beta / 4$ & $(1-\theta)(1-P)$ & $(1-\theta)(1-P)$ \\
\hline \multirow{3}{*}{ CR } & $\mathrm{G} \& \mathbf{P}$ & $\beta / 4$ & 0 & $2 \theta-1$ \\
\hline & $\mathbf{M} \& \mathbf{P}$ & $\beta / 2$ & 0 & 0 \\
\hline & B \& $\mathbf{P}$ & $\beta / 4$ & 0 & 0 \\
\hline
\end{tabular}

Table 1: Shareholder payoff when the manager is conflicted for MB and SB Boards, for FD and $\mathrm{CR}$ regimes, in each state of the firm

resulting from the board's policies described above are provided in Table 1.

\subsubsection{Non-conflicted manager}

FD regime: Now consider the case of a non-conflicted manager. Under the FD regime, discretionary pay is not needed to extract information from the manager. Thus, the SB delegates and the manager accepts the project if and only if it is positive NPV. Because the manager is not conflicted, discretionary compensation is a windfall for the manager. Thus, the MB will offer and the manager will accept discretionary compensation regardless of the project's NPV, and the project will be accepted. The shareholder payoffs resulting from the board's policies are provided in Table 2.

CR regime: Under the $\mathrm{CR}$ regime, because the manager is not conflicted and thus is indifferent between project acceptance and rejection, and because discretionary compensation is blocked, the manager's payoff is not affected by the board's policy. Thus, both SB and MB delegate investment policy to the manager, and the project is accepted if and only if it is positive NPV. The shareholder payoffs resulting from the board's policies are provided in Table 2.

\subsubsection{Optimal ex ante policies}

Shareholder payoffs for each regime and each board type are determined by multiplying the entries presented in Tables 1 and 2 with the corresponding probabilities. Using the resulting shareholder payoffs, the following results are immediate. The proof of this proposition and all the proofs of all other propositions are provided in the Appendix A.

\section{Proposition 1.}




\begin{tabular}{|c|c|c|c|c|}
\hline \multirow[b]{3}{*}{ Regime } & \multirow[b]{3}{*}{ State } & \multirow[b]{3}{*}{ Prob. } & \multicolumn{2}{|c|}{ Board Orientation } \\
\hline & & & $\begin{array}{l}\text { MB } \\
\quad \text { Prob. }\end{array}$ & SB \\
\hline & & & $\delta$ & $1-\delta$ \\
\hline FD & $\begin{array}{l}\text { G \& NP } \\
\text { M \& NP } \\
B \text { \& } \mathbf{N P}\end{array}$ & $\begin{array}{l}(1-\beta) / 4 \\
(1-\beta) / 2 \\
(1-\beta) / 4\end{array}$ & $\begin{array}{c}(2 \theta-1)-P \\
-P \\
-(2 \theta-1)-P\end{array}$ & $\begin{array}{c}\theta \\
1 / 2 \\
(1-\theta)\end{array}$ \\
\hline CR & $\begin{array}{l}\text { G \& NP } \\
\text { M \& NP } \\
B \text { \& } \\
\mathbf{N P}\end{array}$ & $\begin{array}{l}(1-\beta) / 4 \\
(1-\beta) / 2 \\
(1-\beta) / 4\end{array}$ & $\begin{array}{c}\theta \\
1 / 2 \\
(1-\theta)\end{array}$ & $\begin{array}{c}\theta \\
1 / 2 \\
(1-\theta)\end{array}$ \\
\hline
\end{tabular}

Table 2: Shareholder payoff when the manager is not conflicted for MB and SB Boards, for FD and $\mathrm{CR}$ regimes, in each state of the firm

(a) If the board is shareholder oriented, firm value is lower under a CR regime than under an FD regime.

(b) If the board is management oriented and $\beta<\frac{1}{2}$, firm value is higher under a CR regime than under an FD regime.

Proposition 1 shows that conditional on the board being an SB, the FD regime creates more shareholder value than the $\mathrm{CR}$ regime. In contrast, for an $\mathrm{MB}$, constitutional restrictions can be value-increasing if the probability that the manager is conflicted, $\beta$, is sufficiently small. It immediately follows that:

Corollary. Firm value is higher under an FD regime than under a $C R$ regime for $\beta$ sufficiently close to 1 .

Our analysis produces two main insights. First, allowing the boards to have discretion over pay can enhance shareholder value relative to banning discretionary pay via the corporate charter. In fact, somewhat counter-intuitively, such discretion is valuable even if the board is likely to be manager oriented when the likelihood of conflict of interest between the shareholders and managers is sufficiently high. A manager oriented board diverts resources from shareholders via "unnecessary" discretionary pay only when the manager is not conflicted. Thus, when the probability that the manager is conflicted is sufficiently high, it is rational for shareholders to permit even a board known to be manager oriented to offer discretionary compensation.

Second, the payment of discretionary compensation per se does not indicate board capture. In recent work, shareholder activism directed at firms with excess pay, and the support for such activism from shareholders, have been interpreted as evidence of shareholder sophistication and the efficacy of pay-related activism (e.g., Ertimur et al., 2013). However, our analysis indicates that the use of discretionary pay by boards is not indicative of board disloyalty. 


\subsection{Making policy state contingent: the appeal of democracy}

Recall that, in our model, outside shareholders observe a noisy, non-verifiable public signal, $x$, that is informative about the firm's investment prospects. In the next section, we examine how, under shareholder democracy, the outrage constraint can result in restrictions on board behavior conditioned on this signal. We will show that shareholder democracy can only impose signal contingency by blocking discretionary compensation after the low signal and permitting it after the high signal. Moreover, shareholder democracy not only introduces the possibility of signal contingent restraints on boards, it also changes the optimal behavior of boards through the introduction of reputational motivations for board actions. Before we examine the combined effect of democracy on signal-contingency and board behavior in the next section, we would like to isolate the effect of signal contingency. To isolate this effect, in this section, we temporarily suspend our assumption that the public signal, $x$, is not verifiable, and determine the conditions under which signal-contingent charter restrictions, which block discretionary compensation after the low signal $x_{1}$ but permit it after $x_{2}$, increase firm value relative to the two ex ante policies-CR and FD. We term governance under this rather unrealistic charter restriction the "low-signal contingent block regime." Clearly, for the low-signal contingent block regime to be optimal, it must dominate both the $\mathrm{CR}$ regime as well as the FD regime. Because the low-signal contingent block policy coincides with the CR under the low signal, it will dominate CR if and only if

CR the low-signal contingent block policy produces a higher shareholder payoff than CR conditioned on the high signal, $x_{2}$.

Similarly, because the low-signal contingent block policy coincides with FD under the high signal, it will dominate FD if an only if

FD the low-signal contingent block policy produces a higher shareholder payoff than FD conditioned on low signal, $x_{1}$.

For a fixed regime, board type, and state, shareholder payoffs are computed using the payoffs provided in Tables 1 and 2 in Section 2.4, and averaging across the two states of the managerconflicted, which occurs with probability $\beta$, and non-conflicted, which occurs with probability $1-\beta$. Next, we compute signal-conditioned state probabilities. Inspecting Figure 1 shows that, given the low signal, $x_{1}$, the probabilities of reaching states $M$ and $B$ both equal $1 / 4$, and the probability of reaching state $G$ equals 0 . Thus, Bayes rule implies that the probabilities of $M$ and $B$, conditioned on $x_{1}$, both equal $1 / 2$. Similarly, given high signal, $x_{2}$, the probabilities of 


\begin{tabular}{|c|c|c|c|c|c|}
\hline \multirow[b]{4}{*}{ Regime } & \multirow[b]{4}{*}{ State } & & & \multicolumn{2}{|l|}{ Board Orientation } \\
\hline & & \multirow{2}{*}{\multicolumn{2}{|c|}{$\operatorname{Prob}[$ State $\mid x]$}} & MB & SB \\
\hline & & & & \multicolumn{2}{|l|}{ Prob } \\
\hline & & $x_{1}$ & $x_{2}$ & $\delta$ & $1-\delta$ \\
\hline \multirow{3}{*}{ FD } & G & 0 & $1 / 2$ & $\beta \theta(1-P)+(1-\beta)((2 \theta-1)-P)$ & $(1-\beta P) \theta$ \\
\hline & $\mathrm{M}$ & $1 / 2$ & $1 / 2$ & $\beta \frac{1}{2}(1-P)-(1-\beta) P$ & $(1-\beta P) \frac{1}{2}$ \\
\hline & $\mathrm{B}$ & $1 / 2$ & 0 & $\beta(1-\theta)(1-P)-(1-\beta)((2 \theta-1)+P)$ & $(1-\theta)(1-\beta P)$ \\
\hline \multirow{3}{*}{$\mathrm{CR}$} & $\mathrm{G}$ & 0 & $1 / 2$ & $(1-\beta) \theta$ & $\beta(2 \theta-1)+(1-\beta) \theta$ \\
\hline & M & $1 / 2$ & $1 / 2$ & $(1-\beta) \frac{1}{2}$ & $(1-\beta) \frac{1}{2}$ \\
\hline & $\mathrm{B}$ & $1 / 2$ & 0 & $(1-\beta)(1-\theta)$ & $(1-\beta)(1-\theta)$ \\
\hline
\end{tabular}

Table 3: Shareholder payoffs for MB and SB Boards for regimes and states. Shareholder payoffs for the CR and FD regimes for each state are provided in the table. Shareholder payoffs under the low-signal contingent block policy are equal to the CR payoffs when the signal is low, $x_{1}$, and equal to FD payoffs when the signal is high, $x_{2}$. The associated state probabilities are given by the shaded cells in the table.

$G$ and $M$, conditioned on $x_{2}$, both equal $1 / 2$. The payoffs and probabilities so computed are presented in Table 3.

Using the payoffs and probabilities in Table 3, we can compute the expected difference between shareholder payoffs under the low-signal contingent block policy and CR, conditioned on signal, $x_{2}$. In order for condition CR to be satisfied, this difference must be positive. Algebraic simplification shows that the following inequality, (2), is necessary and sufficient for the satisfaction of condition CR.

$$
C_{\mathrm{CR}}=\overbrace{\frac{1}{2}(\delta-\beta P-\beta(1-\delta))\left(\theta-\frac{1}{2}\right)}^{I_{\mathrm{CR}}} \overbrace{+}^{+} \overbrace{\left(\frac{1}{2} \beta(1-P)-\left(\frac{1}{2}+P\right)(1-\beta) \delta\right)}^{\Delta}>0 .
$$

Similarly, the following inequality is necessary and sufficient for the satisfaction of condition FD.

$$
C_{\mathrm{FD}}=\overbrace{\frac{1}{2}(\delta-\beta P+\beta(1-\delta))\left(\theta-\frac{1}{2}\right)}^{I_{\mathrm{FD}}} \overbrace{-}^{-} \overbrace{\left(\frac{1}{2} \beta(1-P)-\left(\frac{1}{2}+P\right)(1-\beta) \delta\right)}^{\Delta}>0 .
$$

In expression (2), the term labeled $\Delta$ represents the gain from the low-signal contingent block policy relative to policy $\mathrm{CR}$ if the signal is uninformative, i.e., $\theta=1 / 2 . I_{\mathrm{CR}}$ and $I_{\mathrm{FD}}$ account for the effect of $\theta$, which reflects the information provided by the signal $x$ regarding the NPV of the project, on the optimality of the low-signal contingent block policy.

Next note that a necessary condition for $C_{\mathrm{CR}}>0$ and $C_{\mathrm{FD}}>0$ is that $C_{\mathrm{CR}}+C_{\mathrm{FD}}>0$. Adding the inequalities in (2) and (3) shows that the condition $C_{\mathrm{CR}}+C_{\mathrm{FD}}>0$ is given by

$$
C_{\mathrm{CR}}+C_{\mathrm{FD}}=I_{\mathrm{CR}}+I_{\mathrm{FD}}=(\delta-P \beta)\left(\theta-\frac{1}{2}\right)>0 .
$$

Thus, the optimality of the low-signal contingent block policy requires that information sig- 
nals are informative. This is an obvious condition for signal contingent contracting to increase value. More interesting is the requirement that $\delta-P \beta>0$, which implies that the likelihood that the board is management oriented, $\delta$, must be large relative to the expected cost of discretionary compensation under the shareholder optimal policy $\beta P$. However, the necessity of $\delta-P \beta>0$ for the optimality of the low-signal contingent block policy does not imply that decreasing $\beta$ or increasing $\delta$ always increases the viability of the low-signal contingent block policy. Conditions (2) and (3) also require that the absolute value of $\Delta$ not be too large. Note that, increasing $\beta$, the probability that the manager is conflicted, increases the gain from permitting discretionary payments, thereby increasing $\Delta$, the gain from adopting the low-signal block policy relative to CR. Similarly, increasing $\delta$, the probability that the board is disloyal, reduces the gain from permitting discretionary compensation, thereby reducing $\Delta$. These assertions are verified by computing marginal effects of $\beta$ and $\delta$ :

$$
\begin{aligned}
& \frac{\partial \Delta}{\partial \beta}=\left(P+\frac{1}{2}\right) \delta+\frac{1-P}{2}>0 \\
& \frac{\partial \Delta}{\partial \delta}=-(1-\beta)\left(P+\frac{1}{2}\right)<0 .
\end{aligned}
$$

Thus, limiting the absolute value of $\Delta$ requires "balancing" $\beta$ and $\delta$. When $\beta$ is much larger than $\delta$, FD dominates the low-signal contingent block policy, and when $\beta$ is much smaller than $\delta$, the CR policy dominates the low-signal contingent block policy.

Next note that there exists a generic range of parameter values under which the low-signal contingent block policy is optimal. The easiest way to see this is to consider parameters in an open neighborhood of any point where $P=0, \beta=\delta /(1+\delta)$, and $\theta-1 / 2>0$. If $P=0$ and $\beta=\delta /(1+\delta)$, then $\Delta=0$ and thus conditions (2) and (3) will be satisfied if and only if $I_{\mathrm{CR}}>0$ and $I_{\mathrm{FD}}>0$. Substituting into the definitions of $I_{\mathrm{CR}}$ and $I_{\mathrm{FD}}$ under these assumptions show that

$$
I_{\mathrm{CR}}=\frac{\delta^{2}\left(\theta-\frac{1}{2}\right)}{1+\delta}>0, \quad I_{\mathrm{FD}}=\frac{\delta\left(\theta-\frac{1}{2}\right)}{1+\delta}>0 .
$$

The continuity of $I_{\mathrm{CR}}$ and $I_{\mathrm{FD}}$ in the parameters of the model thus implies that the set of points in the parameter space that satisfy (2) and (3) contains an open set and is thus generic. These results are summarized in the following proposition.

\section{Proposition 2.}

(i) The low-signal contingent block policy (the state-contingent policy of blocking discretionary compensation only after a low signal realization) produces a higher shareholder payoff than either the CR or the FD regime if and only if conditions (2) and (3) are simultaneously satisfied. There exists a generic subset of parameter values under which these conditions are satisfied. 
(ii) The following conditions are necessary conditions for conditions (2) and (3) to be satisfied, and thus for the optimality of the low-signal contingent block policy:

$$
\theta-\frac{1}{2}>0 \text { and } \delta-P \beta>0 .
$$

For the low-signal contingent block policy to be optimal, the signal must be informative, and the probability that the board is disloyal must be fairly high relative to the expected discretionary payment to the manager made by the SB. In the next section, we develop a model of shareholder democracy in which state contingency is implemented by shareholder outrage rather than the commitment to verifiable state-contingent policies. We show that outrage implementation generates reputational effects which are most costly precisely when board disloyalty is probable. These reputational distortions drastically shrink the range of parameter values over which state contingency is valuable.

\section{Model of corporate democracy: Democratic equilibria}

\subsection{Outrage and reputation}

We take the perspective that shareholder outrage is triggered by suspicion, that is, the shareholders' posterior probability assessment that the board is an MB. Suspicion is rationally generated through the calculus of probabilities via Bayes Rule. We assume that there is an "outrage trigger"- a cutoff value, $\bar{\delta}$, of suspicion, such that suspicion levels in excess of $\bar{\delta}$ generate outrage. Outrage leads to costly sanctions on the board. We assume that boards are extremely sanction averse and are thus constrained to outrage feasible actions, that is, actions that do not generate outrage with positive probability.

\subsubsection{Board preferences}

If the board is an MB (resp. SB), the board strictly prefers actions which produce a higher payoff to the manager (shareholders) to all action that produces a lower payoff to the manager (shareholders). Actions which maximize the payoff to the manager (shareholders) subject to the outrage feasibility constraint are termed outrage feasible best replies.

When choosing between outrage feasible best replies, the board strictly prefers any action which produces lower suspicion to any action which produces higher suspicion. An outrage feasible best reply that minimizes suspicion over the set of all outrage feasible best replies is termed minimal suspicion outrage feasible best reply. Thus, boards always choose minimal 
suspicion outrage feasible best replies. This assumption can be justified by a model of shareholder outrage in which the outrage threshold is "nearly" non-stochastic. Informally speaking, in such an environment, among actions that maximize the board's objective function and are outrage feasible, the board will have a slight bias toward those that minimize suspicion because of a vanishingly slight uncertainty regarding shareholders' outrage threshold. ${ }^{10}$ The MB (SB) board is indifferent over all actions that produce the same payoff to the manager (shareholders) and the same suspicion.

\subsection{Equilibrium}

A candidate equilibrium is a three-tuple, with three components, (a) shareholder beliefs: these are assignments of suspicion levels to each history in the shareholders' information set. (b) board strategies: a map from the board's information sets into board actions and (c) manager strategies: a map from those managerial information sets at which the manager decides on investment policy to an accept/reject decision. A shareholder democracy equilibrium is a candidate equilibrium which satisfies the conditions for a Perfect Sequential Equilibrium (PSE) (Grossman and Perry, 1986).

In some cases, multiple equilibria exist which produce different payoffs for shareholders. In these cases we focus on the equilibria that produce the highest shareholder payoffs. This motivates the following definition-A shareholder democracy equilibrium is a shareholder optimal democratic equilibrium if there does not exist another shareholder democracy equilibrium that produces a strictly higher ex ante payoff for shareholders. ${ }^{11}$

The PSE concept requires that, at all off-equilibrium histories of the game, uninformed agents' beliefs must be consistent, if consistent beliefs for that history exist. A belief is a probability distribution over the types of the informed agent. A belief is consistent if, given the probability distribution, there exists a weak best response for the uninformed party such that, for that response, the support of the probability distribution contains only those types which would weakly gain from deviating from the equilibrium.

In essence, consistent beliefs are self-fulfilling beliefs. If the uninformed party believes that a set of types is weakly willing to deviate from the equilibrium to the off-equilibrium history and acts accordingly, that set of types (and only that set of types) will be weakly willing to deviate.

\footnotetext{
${ }^{10}$ See Online Supplement A for further discussion.

${ }^{11}$ When equilibrium is qualified by a restriction, shareholder optimality requires that the equilibrium is optimal over the restricted set. e.g, if the restriction is "compensation is blocked" then a shareholder optimal equilibrium is an equilibrium with the property that no equilibrium in which compensation is blocked produces a higher payoff.
} 
If no consistent beliefs exist, which will be the case, for example, if the payoff from deviation is strongly dominated, then PSE places no restriction on off-equilibrium beliefs. If multiple consistent beliefs exist, then any one of the consistent beliefs can be held by the uninformed agent. For the rationale for this equilibrium concept and more technical details, see Grossman and Perry (1986).

\subsection{Shareholder information sets}

The basic information structure for the model is detailed in Section 2 and Figure 1. At this point, we need to work out the implications of this structure for the ex post information that is available to shareholders when assessing the board. From our earlier analysis, we see that if positive discretionary compensation is offered, the level of compensation must be set at $D_{c}=P$. Any other discretionary payment would reveal that the board is not shareholder-oriented and thus violate the outrage feasibility constraint. ${ }^{12}$ Thus, the board will either offer discretionary compensation equal to $P$ or not offer discretionary compensation at all. This greatly restricts the possible shareholder information sets. The number of information sets is also restricted because shareholders cannot distinguish between (a) no discretionary pay being offered and the project being rejected by the manager, and (b) discretionary pay being offered and the project being rejected by the manager, and (c) the project being rejected by the board. Thus, the information available to shareholders at the time they evaluate the loyalty of the board will consist of a public signal and their observation of compensation/investment policy. The shareholder observed compensation/investment policy will be one of the following:

(a) project rejection: the project is rejected in which case discretionary compensation is never paid,

(b) project acceptance with discretionary compensation: the project is accepted and the manager receives a discretionary compensation payment of $P$,

(c) project acceptance without discretionary compensation: the project is accepted and the manager does not receive a discretionary compensation payment.

In the sequel, we will refer to shareholder information sets and shareholder observed compensation policies simply as "histories." Through the outrage constraint, shareholder beliefs

\footnotetext{
${ }^{12}$ Offering discretionary compensation $D_{c} \neq P$ produces strictly lower shareholder welfare than both not offering discretionary compensation at all or offering discretionary compensation $D_{c}=P$. Thus, if we extended the action space to include, $D_{c} \neq P$, it would be easy to show that no equilibria exist in which offering discretionary compensation unequal to $P$ occurs in equilibrium with positive probability. Thus, including all possible levels of discretionary compensation in the action space would make the action space for the board infinite, require additional notation, and in the end, have no effect on our conclusions.
} 
associated with a given history can block board actions that lead with positive probability to that history.

\subsection{Parameter restrictions}

Finally, we impose some additional restrictions on the parameter space of the game: (a) $\delta<$ $\bar{\delta}<1$, (b) $\beta<\bar{\beta}=\frac{1}{3}$.

Assumption (a) implies that there is scope for differences in the shareholder information sets produced by $\mathrm{MB}$ and $\mathrm{SB}$, yet reputation matters to the board. If $\bar{\delta}<\delta$, since the expectation of a posterior probability (i.e., suspicion) always equals the prior probability, it would have to be the case that at some history reached with positive probability, shareholder suspicion exceeded the outrage threshold. Thus, no board strategy would satisfy outrage feasibility. If $\bar{\delta}=\delta$, then for the same reason as stated above, suspicion would have to be the same at every history reached with positive probability. In either case, the model would not be very interesting.

Assumption (b) ensures that the likelihood of the manager being conflicted is not too high. This is the interesting case because, the higher the likelihood that the manager is conflicted, the less likely it is that grants of discretionary compensation are inappropriate. In fact if $\beta=1$, the problem we model vanishes. In this case, it is common knowledge that paying discretionary compensation increases firm value and the terms of shareholder-value-maximizing discretionary compensation are also common knowledge. Thus, the MB and the SB would follow the same policy: using efficient discretionary compensation to induce the manager to reveal project information.

When $\beta$ is high but less than 1 , the probability that the manager is conflicted is large. Thus, shareholders are not "surprised" by discretionary compensation grants even following adverse signals relating to firm performance. If the MB also pays discretionary compensation to the manager in the (unlikely) event that the manager is not conflicted, the likelihood that the MB pays discretionary compensation will not be much higher than the likelihood that the SB pays discretionary compensation. Thus, paying discretionary compensation will not significantly increase shareholder suspicion. However, if the MB always rejects the project when the manager is conflicted, because being conflicted is very probable, the MB's likelihood of rejection will be much higher than the SB's. In this case, shareholder outrage would be most pronounced when the project is rejected rather than when discretionary compensation is paid. Since our interest in this paper is to analyze the consequences of outrage triggered by compensation policy rather than project accept/reject decisions, high $\beta$ parameterizations do not capture the situation we 
aim to model. ${ }^{13}$

It is interesting to consider the $\beta<1 / 3$ restriction in light of Proposition 1 . The continuity of shareholder payoffs in the probability that the board is disloyal, $\delta$, and Proposition 1.a imply that FD always dominates CR when $\delta$ is sufficiently close to 0 . Continuity, the parameter restriction, $\beta<1 / 3$, and Proposition 1.b imply that CR always dominates FD when $\delta$ is sufficiently close to 1 . In the subsequent analysis, we aim to compare the best of these two policies, FD and CR, from a shareholder perspective, with the outcome of a shareholder democracy where shareholders' ex post evaluations of board loyalty constrains discretionary compensation policy.

\section{Democratic equilibria}

\subsection{Effect of outrage on board behavior}

We initiate our analysis by deriving an "obvious result," but one which will permit us to reduce the number of equilibrium configurations we need to consider.

Lemma 1. In any shareholder democracy equilibrium, accepting the project and not paying discretionary compensation is outrage feasible whenever both rejecting the project, and accepting the project while paying discretionary compensation, are outrage feasible.

The logic behind the Lemma is straightforward. Outrage feasibility implies that board actions that lead to histories that violate the outrage constraint are off the equilibrium path. In order for accepting the project without discretionary compensation to be infeasible under the outrage constraint, shareholders' beliefs conditioned on observing project acceptance without discretionary compensation must assign a high probability to board disloyalty. However, accepting the project without offering discretionary compensation is sometimes the unique optimal action for the SB and is never the unique optimal action for the MB. For this reason, the consistency conditions on off-equilibrium beliefs imposed by PSE cannot rationalize shareholder beliefs that associate accepting the project without paying discretionary compensation with disloyalty.

The discussion in Section 3.3 showed that there are only three shareholder observable compensation/investment policies. This implies, given the restrictions on the patterns of outrage

\footnotetext{
${ }^{13}$ The restriction of $\beta<1 / 3$ imposed in this manuscript is somewhat stronger than required to keep the focus of shareholder suspicion on discretionary compensation payments. The stronger restriction greatly simplifies the analysis by ensuring pure-strategy solutions when discretionary compensation is not blocked by shareholder outrage. For a slightly more general specification, see the working paper version of this paper.
} 
feasibility imposed by Lemma 1 , that for each public signal, $x$, there are only four possible types of equilibrium configurations: outrage does not block any compensation/investment policy; outrage blocks project acceptance with discretionary compensation; outrage blocks project acceptance completely because acceptance with or without discretionary compensation payments is not outrage feasible; or outrage blocks project rejection completely because project rejection is not outrage feasible. In the later two configurations, shareholder outrage forces project choice rather than restricts compensation policy. Because this paper is concerned the effect of shareholder democracy on compensation rather than project selection, we will concentrate on the first two equilibrium configurations. Thus, we consider, for each public signal, two types of equilibria: equilibria in which discretionary compensation is not blocked by the outrage constraint and equilibria in which the outrage constraint blocks discretionary compensation.

\subsection{Equilibrium configurations}

\subsubsection{Democratic equilibria in which discretionary compensation is not blocked by outrage}

We first characterize equilibria in which outrage does not block discretionary compensation. In these equilibria, SB are not blocked from employing discretionary compensation and will use discretionary compensation when it increases firm value. Thus, deviations from shareholder optimum policies will only occur when the board is management oriented. As pointed out in the discussion of full delegation in Section 2.4, even in the absence of any reputational concerns generated by shareholder outrage, an MB has an incentive to abuse discretionary compensation by offering it when it is not necessary, i.e. when the manager is not conflicted. In this section, we show that democracy exacerbates this misalignment-under democracy the MB not only has an incentive to pay discretionary compensation when such compensation does not increase firm value, but also to withhold discretionary compensation when it does increase firm value.

Proposition 3. In any shareholder democracy equilibrium in which discretionary pay is offered after either public signal,

a. an MB offers and pays discretionary compensation, leading to acceptance of the project regardless of its NPV, whenever the manager is not conflicted, and ensures that the project is rejected when the manager is conflicted.

b. an SB offers discretionary compensation if and only if the manager is conflicted, leading to project acceptance if and only if the project has positive NPV.

c. shareholder payoffs are strictly lower under democracy than under a full delegation regime. 
The intuition for Proposition 3 is that under democracy, board reputation with shareholders is important. Paying discretionary compensation is a more suspicious action than rejecting the project. Thus, withholding discretionary compensation and rejecting the project when the manager is conflicted, while paying discretionary compensation when the manager is not conflicted, permits the manager oriented board to both limit the overall use of discretionary compensation and, at the same time, maximize the manager's payoff. Since paying discretionary compensation to conflicted managers and extracting their private information about project NPV has significant benefits to shareholders, this withholding of compensation from conflicted managers lowers shareholder welfare relative to that under full delegation.

\subsubsection{When outrage blocks discretionary pay}

When shareholders' posterior assessment associated with paying discretionary compensation crosses the outrage constraint, neither the MB nor the SB will pay discretionary compensation. Thus, the policies of both the MB and the SB deviate from the shareholder optimum policy. While the $\mathrm{CR}$ regime, which disallows discretionary compensation, also deviates from the shareholder optimal policy by banning discretionary compensation, the following proposition shows that the reputational concerns induced by shareholder democracy leads to additional distortions when the public signal is high, that is, $x=x_{2}$.

Proposition 4. Shareholder optimal democratic equilibria in which the outrage constraint blocks discretionary pay have the following properties:

- After the high public signal, $x=x_{2}$ :

(a) The MB always rejects the project when the manager is conflicted. When the manager is not conflicted, the MB randomizes, delegating investment policy to the manager with probability $\alpha$ and forcing project acceptance regardless of NPV with probability $1-\alpha$, where

$$
\alpha=1-\frac{\beta}{1-\beta} \frac{1}{1-(\theta-1 / 2)} .
$$

(b) When the manager is not conflicted, the SB delegates investment policy to the manager. When the manager is conflicted, the SB accepts the project when the board's private signal equals $G$ and rejects the project when the private signal is $M$.

(c) In equilibrium, the choice between acceptance and rejection of the investment is not informative about board loyalty. 
(d) Shareholder payoffs are lower under democracy than they would have been under the charter restriction policy.

- After the low public signal, $x=x_{1}$ :

(a) Both the MB and SB follow the shareholder optimal outrage feasible policy of delegating investment policy to the manager when the manager is not conflicted and, when the manager is conflicted, rejecting the project. In equilibrium, the choice between acceptance and rejection is not informative about board loyalty.

(b) Shareholder payoffs under democracy equal shareholder payoffs under charter restrictions.

The basic tension that drives Proposition 4 is the MB's preference for project rejection when the manager is conflicted, and how this preference aligns with SB preferences. When the manager is not conflicted, the board's project acceptance is effectively conditional on the project's NPV being positive. However, when the manager is conflicted, the outrage block on discretionary compensation makes it impossible to incorporate the manager's private information into the accept/reject decision. So an SB will base its accept/ reject decision on its imperfect signal about project NPV. Because the manager is conflicted due to his "quiet life" preferences, the MB will reject the project. When the public signal is low, $x=x_{1}$, project NPV is ex ante nonpositive under both possible board signals $M$ and $B$. Thus when the manager is conflicted, SB and MB preferences align and favor rejection. This alignment supports a shareholder optimal outcome (subject to the constraint on discretionary compensation being blocked) in which the MB and SB follow the same policy. In contrast, under the high public signal, one of the possible board signals, $G$, corresponds to the expected NPV of the project being positive. Thus, when the manager is conflicted, the SB will sometimes force project acceptance. Hence, if the MB rejects the project whenever the manager is conflicted but follows the shareholder optimal delegation policy when the manger is not conflicted, the MB would be more likely to reject the project than an SB, and project rejection would increase suspicion. To counter this increase in suspicion, the MB lowers its probability of rejection by sometimes accepting negative NPV projects when the manager is not conflicted. Such acceptances lower shareholder welfare relative to that under charter restriction. The equilibrium probability of accepting negative NPV projects when the manager is non-conflicted is set so that the MB and SB have the same probability, conditioned on $x_{2}$, of rejection, and thus, again rejection is not informative.

An important implication of Propositions 3 and 4 is that, conditional on discretionary pay 
being either outrage feasible under both public signals or being blocked under both, democracy is dominated from the perspective of shareholder welfare. Thus, for democracy to increase shareholder value, it must impose "signal-contingent" restrictions on discretionary compensation policy, restricting discretionary compensation after some public signals and permitting it after others. Therefore, outrage must block discretionary compensation under one of the public signals and permit it under the other. What sort of signal-contingent restrictions will democracy impose? Since outrage is triggered by suspicion, this reduces to the question: under which signal will discretionary compensation trigger a higher level of suspicion? The answer to this question is not surprising: paying discretionary compensation is more suspicious after the low signal, $x_{1}$.

Proposition 5. In any shareholder optimal democratic equilibrium in which discretionary compensation is paid after both signals $x_{1}$ and $x_{2}$, paying it after the receipt of a low signal is the most suspicious action the board undertakes.

The logic behind this proposition is straightforward: Compared with an $\mathrm{MB}$, the SB pays discretionary compensation with a higher probability when the signal is high, $x_{2}$, than when it is low, $x_{1}$. Thus, paying discretionary compensation generates more suspicion when it is paid after the low signal than when it is paid after the high signal.

An important empirical implication follows from the same logic that is behind Proposition 5. The proposition follows from the fact that discretionary compensation is more likely to be paid after firms receive good news about future prospects. Note that this prediction crucially depends on the "quiet life" assumption regarding managerial preferences. Under this assumption, discretionary compensation is paid to induce the manager to undertake positive NPV projects, and shareholders are least suspicious of such compensation under the high signal, when their assessment of the probability that the project is positive NPV is high. Under the contrasting "empire building" assumption, discretionary compensation is paid to induce the manager to reject negative NPV projects. Thus, under this assumption, shareholders would be less suspicious of discretionary compensation after a low signal, because such a signal indicates that project NPV is likely to be negative. Hence, an empire-building version of this model predicts that discretionary compensation is more likely to be paid after firms receive bad news about future prospects. This implies that empirically testing the relationship between firm performance and the payment of discretionary compensation can provide evidence on the relative prevalence of quiet life versus empire building managerial preferences.

A straightforward consequence of Proposition 5 and the belief consistency condition im- 
posed by the definition of a Perfect Sequential Equilibrium is that, if a shareholder democracy equilibrium blocks discretionary compensation conditioned on the high signal $x_{2}$ (under which making discretionary payments to the manager is less suspicious), the equilibrium must also block discretionary payments conditioned on the low signal, $x_{1}$ (under which discretionary compensation is more suspicious).

Lemma 2. No shareholder democracy equilibrium exists in which discretionary compensation is blocked after signal $x_{2}$ but not blocked after signal $x_{1}$.

\section{A role for democracy?}

Our results have shown that, for any given signal, ex ante commitment regimes always dominate democracy. However, ex ante restrictions are not signal-contingent. Democratic equilibria, in contrast, can impose signal-dependent constraints on board behavior. As shown in Section 2.5, if we ignore the distortion costs of democracy, signal-conditioned restrictions can, in some cases, increase firm value. Thus, the natural question to ask is whether the signal contingency produced by democracy is ever worth the attendant distortion costs. In this section, we answer this question in the affirmative but show that the conditions required to make democracy optimal are quite stringent.

To investigate whether democracy is sometimes better than commitment we define "better" in a way that is most generous towards democratic governance.

Definition. Shareholder democracy is the optimal governance regime if there exists any outrage threshold under which there is a shareholder democracy equilibrium which produces higher firm value than both charter restrictions and full delegation.

Note that the standard we are imposing for democratic governance to create value is "liberal" in that we tune the outrage threshold to a value that maximizes shareholder value, and restrict attention to the democracy equilibrium that produces the highest ex ante payoff to shareholders.

We have determined the shareholder optimal equilibria for each signal in Propositions 3 and 4. These propositions show that when outrage either allows discretionary compensation, or blocks it, after both signals, shareholder democracy is inferior from the perspective of shareholder welfare to one of the two ex ante regimes, FD and CR. Hence shareholder democracy can dominate both of these regimes only when it generates a signal-contingent block on discretionary compensation. Lemma 2 shows that such a state contingent block must take the form of 
blocking discretionary compensation after the low signal $x_{1}$ but not blocking discretionary compensation after high signal $x_{2}$. Next note that there always exists an outrage threshold between the suspicion levels generated by discretionary compensation under the high and low signals. It is only possible for shareholder democracy to improve shareholder welfare when the outrage threshold lies between these two suspicion levels and discretionary compensation is blocked by the outrage constraint after signal $x_{2}$ and not blocked by the outrage constraint after signal $x_{2}$.

Therefore, to identify the conditions under which shareholder democracy is optimal, we need only compare shareholder welfare under the two ex ante regimes, FD and CR, with that in the shareholder optimal democratic equilibria in which outrage blocks discretionary compensation after the low public signal, $x_{1}$ and permits discretionary compensation after the high public signal, $x_{2}$. Using the characterizations of board behavior developed in Propositions 3 and 4 , we first compute the shareholder payoffs conditioned on the public and board signals. These payoffs are presented in Table 4.

\begin{tabular}{ccccc}
\hline & & & \multicolumn{2}{c}{ Board Orientation } \\
\cline { 4 - 5 } Disc. Comp. & Event & Prob. & MB & SB \\
\hline \multirow{2}{*}{ permitted } & $G \& x_{2}$ & $1 / 4$ & $(1-\beta)((2 \theta-1)-P)$ & $\beta(\theta(1-P))+(1-\beta) \theta$ \\
& $M \& x_{2}$ & $1 / 4$ & $-(1-\beta) P$ & $\beta\left(\frac{1}{2}(1-P)\right)+(1-\beta) \frac{1}{2}$ \\
\hline \multirow{2}{*}{ blocked } & $M \& x_{1}$ & $1 / 4$ & $(1-\beta) \frac{1}{2}$ & $(1-\beta) \frac{1}{2}$ \\
& $B \& x_{1}$ & $1 / 4$ & $(1-\beta)(1-\theta)$ & $(1-\beta)(1-\theta)$ \\
\hline
\end{tabular}

Table 4: Shareholder signal-contingent payoffs under democracy.

Next, we take expectations over the signal contingent payoffs to determine ex ante shareholder payoff under the shareholder democracy regime, and compare this payoff with shareholder payoffs under the two ex ante regimes, CR and FD. The question we ask is: when does shareholder democracy produce higher shareholder payoffs than in the two ex ante regimes. The following proposition provides some insight into this question.

Proposition 6. Shareholder democracy is not optimal if either (a) $\delta<P \beta$, or (b) $\delta>\beta$, or (c) $\theta-\frac{1}{2}<\frac{\beta}{1-\beta}$.

These conditions illustrate the limitations of shareholder democracy as an efficient check on board opportunism. Condition (a) simply follows from noting that the shareholder payoff from democracy is always strictly smaller than the shareholder payoff under low-signal contingent block regime, and applying the necessary condition for the optimality of the low-signal contingent regime provided in Proposition 2.ii. This shows that democracy can never be optimal if the probability of board disloyalty is sufficiently small in relation to $P$ and $\beta$. Condition (b) 
shows that $\delta$ also cannot be very high in relation to $\beta$. Together, these two conditions confirm the intuition from equations (2) and (3) in Section 2.5 that $\delta$ cannot be far away from $\beta$ for state contingent policies to dominate commitment policies. Condition (b), in particular, highlights the fact that the arguments for shareholder democracy based on pervasive board capture and grants are not confirmed by our analysis. In fact, because of the distortionary effect of democracy on the behavior of disloyal boards, the higher the probability that the board is disloyal, the larger the losses from policy distortion associated with MB boards that are induced by democratic governance. At the same time, the expected benefit of democracy relative to charter restrictions is small if the probability that offering discretionary compensation is shareholder optimal, i.e., $\beta$ is small.

Finally, Condition (c) shows that democracy is also never optimal when signal informativeness is low relative to the probability that the manager is conflicted. The benefit of an outrage constraint on compensation depends on how effectively the shareholders' signal—the trigger for outrage-identifies the conditions of the firm under which discretionary compensation is particularly unlikely to be optimal for the shareholders. This effectiveness is measured by $\theta-1 / 2$. One cost of democracy is that outrage may block the efficient use of discretionary compensation to induce information revelation by conflicted managers. Since the probability that the manager is conflicted is given by $\beta$, this implies that the effectiveness of the shareholder signal must be large relative to the odds that the manager is conflicted, $\beta /(1-\beta) .{ }^{14}$

The existence of a range of parameter values for which none of the conditions in Proposition 6 holds is necessary for the existence of a shareholder democracy equilibrium that produces higher shareholder welfare than both CR and FD, but is hardly sufficient. Imposing all of the incentive constraints required to support a shareholder welfare improving democratic equilibrium in fact requires a very careful choice of parameters for the model. This supports our intuition that shareholder democracy might be optimal for some firms but that, once the costs of democratic distortion are considered, democracy is not likely to be the sort of globally and robustly optimal governance mechanism that should be legislated. ${ }^{15}$

\footnotetext{
${ }^{14}$ Note that this condition alone implies that democracy can never be optimal if $\beta=\frac{1}{3}$.

${ }^{15}$ For a more detailed discussion of the parameter space supporting shareholder democracy as an optimal governance mechanism, see the working paper version of this paper.
} 


\section{Conclusion}

Shareholder democracy constrains board discretionary compensation policy based on ex post evaluations by relatively uninformed shareholders. It is apparent that, if boards are loyal to shareholders and thus pursue shareholder value maximization, shareholder democracy cannot improve shareholder welfare as it substitutes the judgments of uninformed agents for the judgments of better informed agents with the same objectives. Our contribution is to show that when boards are disloyal, shareholder democracy also imposes significant costs: the reputational incentives engendered by democracy lead management-captured boards to take actions even more detrimental to shareholder welfare than they would have in a full-delegation "director primacy" regime. Thus, legally mandating increased shareholder influence over compensation policy is problematic.

\section{References}

Bainbridge, Stephen, "The case for limited shareholder voting rights," UCLA Law Review, 2005, 53, 601 .

Bebchuk, Lucian A. and Jesse M. Fried, "Pay without performance: Overview of the issues," Journal of Applied Corporate Finance, 2005, 17 (4), 8-23.

Bertrand, Marianne and Sendhil Mullainathan, "Enjoying the quiet life? Corporate governance and managerial preferences," Journal of Political Economy, 2003, 111 (5), 1043-1075.

Bolton, Patrick, Jose Scheinkman, and Wei Xiong, "Pay for short-term performance: executive compensation in speculative markets," Technical Report, National Bureau of Economic Research 2006.

Cai, Jie and Ralph Walkling, "Shareholders' say on pay: Does it create value?," Journal of Financial and Quantitative Analysis, 2011, 49, 299-339.

_, Jacqueline L. Garner, and Ralph A. Walkling, "Electing directors," The Journal of Finance, 2009, 64 (5), 2389-2421.

Cohn, Jonathan B. and Uday Rajan, "Optimal corporate governance in the presence of an activist investor," Review of Financial Studies, 2013, 26 (4), 985-1020.

De Angelis, David and Yaniv Grinstein, "Pay for the right performance," 2012. Johnson School Research Paper Series: 03-2011.

Del Guercio, Diane, Laura Wallis, and Tracie Woidtke, "Do boards pay attention when institutional investors just vote no?: CEO and director turnover associated with shareholder activism," Journal of Financial Economics, 2008, 90, 84-103.

Eisfeldt, Andrea L. and Adriano A. Rampini, "Managerial incentives, capital reallocation, and the business cycle," Journal of Financial Economics, 2008, 87 (1), 177-199. 
Ertimur, Y., F. Ferri, and D. Oesch, "Shareholder votes and proxy advisors: Evidence from say on pay," Journal of Accounting Research, 2013, 51, 951-996.

Ferri, Fabrizio and David A. Maber, "Say on pay votes and CEO compensation: Evidence from the UK," Review of Finance, 2013, 17 (2), 527-563.

Fischer, Paul E., Jeffrey D. Gramlich, Brian P. Miller, and Hal D. White, "Investor perceptions of board performance: Evidence from uncontested director elections," Journal of Accounting and Economics, 2009, 48 (2), 172-189.

Fisman, Ray, Rakesh Khurana, Matthew Rhodes-Kropf, and Soojin Yim, "Governance and CEO turnover: Do something or do the right thing?," Management Science, 2014, 60, 319-337.

Grossman, Sanford J. and Motty Perry, "Perfect sequential equilibrium," Journal of Economic Theory, 1986, 39 (1), 97-119.

Harford, Jarrad, "Takeover bids and target directors' incentives: The impact of a bid on directors' wealth and board seats," Journal of Financial Economics, 2003, 69 (1), 51-83.

Iliev, Peter and Michelle Lowry, "Are mutual funds active voters?," Review of Financial Studies, 2015, 28 (2), 446-485.

_, Karl V. Lins, Darius P. Miller, and Lukas Roth, "Shareholder voting and corporate governance around the world," Review of Financial Studies, 2015, 28 (8), 2167-2202.

Inderst, Roman and Holger M Mueller, "CEO replacement under private information," Review of Financial Studies, 2010, 23 (8), 2935-2969.

Jensen, Michael C., "The modern industrial revolution, exit, and the failure of internal control systems," the Journal of Finance, 1993, 48 (3), 831-880.

Krugman, Paul, “The outrage constraint,” The New York Times, 2002, 23, A17.

Larcker, D., A. McCall, and G. Ormazabal, "Outsourcing shareholder voting to proxy advisory firms,” 2014. Stanford GSB Research Paper No. 2105R.

Levit, Doron and Nadya Malenko, "The labor market for directors and externalities in corporate governance," The Journal of Finance, 2016, 71 (2), 775-808.

Murphy, Kevin J., "Explaining executive compensation: Managerial power versus the perceived cost of stock options," The University of Chicago Law Review, 2002, pp. 847-869.

Narayanan, M. P., "Managerial incentives for short-term results," The Journal of Finance, $1985,40(5), 1469-1484$.

Song, Fenghua and Anjan V. Thakor, "Information control, career concerns, and corporate governance," The Journal of Finance, 2006, 61 (4), 1845-1896.

Stein, Jeremy C., "Takeover threats and managerial myopia," The Journal of Political Economy, 1988, pp. 61-80.

Williamson, Oliver E., The Economics of Discretionary Behavior: Managerial Objectives in a Theory of the Firm, Prentice-Hall, 1964. 


\section{A Appendix: Proofs of results}

\section{Preliminaries}

In order to track the histories of the game at which shareholders form beliefs, we require some notation. As discussed in Section 3.3, for each fixed public signal, there are three possible shareholder-observed compensation/investment policies: project rejection, project acceptance with discretionary compensation, and project acceptance without discretionary compensation. We represent project rejection by $\mathbf{R}$, project acceptance with discretionary compensation by $\mathbf{A}^{+}$, and project acceptance without discretionary compensation by $\mathbf{A}^{-}$. Given that there are two possible public signals, $x_{1}$ and $x_{2}$, there are six information sets at which shareholders form posterior beliefs concerning board loyalty: $\left(x_{1}, \mathbf{R}\right),\left(x_{1}, \mathbf{A}^{+}\right),\left(x_{1}, \mathbf{A}^{-}\right),\left(x_{2}, \mathbf{R}\right),\left(x_{2}, \mathbf{A}^{+}\right),\left(x_{2}, \mathbf{A}^{-}\right)$.

\section{Proofs}

Proof of Proposition 1. First consider part (a). Note first from Table 2 that when the manager is not conflicted, shareholder payoff is the same in every state of the firm for FD and CR regimes under an SB. Thus, we need only to calculate the expected payoffs under the two regimes when the manager is conflicted. From the expected payoff to shareholders using the state-by-state payoffs in Table 1, it can be shown that the condition required for shareholder value to be higher in the FD regime is

$$
(1 / 2)\left(\frac{1-P}{2}\right)+\frac{1}{4}((1-\theta)(1-P))+\frac{1}{4}(\theta(1-P))>\frac{1}{4}(2 \theta-1) .
$$

The inequality in (A-1) can be rewritten as

$$
\left(\frac{3}{4}-\frac{\theta}{2}\right)>\frac{P}{2}
$$

It is easy to check that the condition holds given (1).

Now consider part (b). Computing the expected payoff to shareholders under FD and MB, Sh:MB , using the state-by-state payoffs in Table 1 and Table 2 yields

$$
\begin{aligned}
u_{\mathrm{Sh}: \mathrm{MB}}^{\mathrm{FD}}=(1-\beta) & \left(\frac{1}{4}(2 \theta-1)+\frac{1}{4}(1-2 \theta)-P\right) \\
& +\beta\left(\frac{1}{4} \theta(1-P)+\frac{1}{4}(1-\theta)(1-P)+\frac{1}{2}\left(\frac{1-P}{2}\right)\right) .
\end{aligned}
$$

Similarly, using Table 1 and Table 2, we obtain the payoffs under MB and CR, $u_{\mathrm{Sh}: \mathrm{MB}}^{\mathrm{CR}}$ :

$$
u_{\mathrm{Sh}: \mathrm{MB}}^{\mathrm{CR}}=(1-\beta)\left(\frac{1}{4} \theta+\frac{1}{4}((1-\theta))+\frac{1}{2} \frac{1}{2}\right)+\beta 0
$$

After some manipulation, we obtain

$$
\begin{aligned}
& u_{\mathrm{Sh}: \mathrm{MB}}^{\mathrm{FD}}-u_{\mathrm{Sh}: \mathrm{MB}}^{\mathrm{CR}} \gtreqless 0 \\
& \Leftrightarrow\left(\beta-\left(\frac{1}{4}(1-\theta)+\frac{1}{4} \theta+\frac{1}{4}\right)\right) \gtreqless P\left((1-\beta)+\beta\left(\frac{1}{4}(1-\theta)+\frac{1}{4} \theta+\frac{1}{4}\right)\right) .
\end{aligned}
$$


Hence, the results easily follow.

Proof of Lemma 1. For a given signal, $x$, consider a candidate equilibrium in which accepting the project without paying discretionary compensation is not outrage feasible, the candidate equilibrium has assigned suspicion to $\left(x, \mathbf{A}^{-}\right)$of $\hat{\delta}^{*}\left(x, \mathbf{A}^{-}\right)$which satisfies, $\hat{\delta}^{*}\left(x, \mathbf{A}^{-}\right)>\bar{\delta}$. Because $\left(x, \mathbf{A}^{-}\right)$is blocked by the outrage constraint, this history is off the equilibrium path. This belief is not consistent in the sense of Grossman and Perry (1986): Given this belief and the outrage constraint, the set of types that would weakly gain from defecting to an action which would lead to $\left(x, \mathbf{A}^{-}\right)$is empty. Thus, this belief, $\hat{\delta}^{*}\left(x, \mathbf{A}^{-}\right)$, will satisfy the PSE conditions if and only if no consistent belief can be assigned to $\mathbf{A}^{-}$.

Consider the candidate consistent belief assignment $\hat{\delta}^{o}\left(x, \mathbf{A}^{-}\right)=0$. This candidate consistent belief is clearly less than the outrage threshold. Thus, under the candidate consistent belief, reaching $\left(x, \mathbf{A}^{-}\right)$is outrage feasible. By hypothesis, outrage does not block reaching $\left(x, \mathbf{A}^{+}\right)$or $(x, \mathbf{R})$. Thus, in the candidate equilibrium, when the manager is not conflicted, the manager's payoff is maximized over outrage feasible policies by offering discretionary compensation. When the manager is conflicted, the manager's payoff is maximized by either rejecting the project or offering discretionary compensation. In either case, the manager's payoff is strictly higher than it would be if history $\left(x, \mathbf{A}^{-}\right)$were reached.

Thus, under the candidate consistent belief, the MB will not defect from the equilibrium to any action that leads to $(x, \mathbf{A}-)$ with positive probability. Under the candidate consistent belief, the SB's optimal action is to not offer discretionary compensation if and only if the manager is not conflicted. This strategy will lead to $\left(x, \mathbf{A}^{-}\right)$with positive probability. Thus, given the candidate consistent belief, the only type defecting from the candidate equilibrium will be the SB when the manager is not conflicted.

Conditioned on the set of defecting types under the candidate consistent belief, Bayes rule will assign zero probability to the board being disloyal when $\left(x, \mathbf{A}^{-}\right)$is reached. Thus, the candidate consistent belief, $\hat{\delta}^{o}\left(x, \mathbf{A}^{-}\right)$equals the belief produced by Bayes rule conditioned on the set of defecting types generated by the candidate consistent belief. Thus, $\hat{\delta}^{o}\left(x, \mathbf{A}^{-}\right)$is a consistent belief assignment. Hence, the candidate equilibrium fails to satisfy the conditions for a PSE.

Proof of Proposition 3. We need to compute the odds ratios associated with the three possible compensation/investment histories that shareholders can observe, conditioned on the two public signals, $x_{1}$ and $x_{2}$. We start by considering signal $x_{2}$ and explain in detail the odds ratio associated with rejecting the project after public signal $x_{2}, o\left(x_{2}, \mathbf{R}\right)$. Since the explanation is the same for all of the remaining odds ratio calculations, we will simply present these without detailed derivations.

The odds ratio for $\left(x_{2}, \mathbf{R}\right)$ is the ratio between the posterior probability that the board is $\mathrm{MB}$ conditioned on $\left(x_{2}, \mathbf{R}\right)$, and the posterior probability that the board is SB conditioned on $\left(x_{2}, \mathbf{R}\right)$. By Bayes rule, this ratio is equal to the ratio of the joint probabilities. Thus, the odds ratio is 
given by

$$
o\left(x_{2}, \mathbf{R}\right)=\frac{\mathbb{P}\left[\mathrm{MB} \& x_{2} \& \mathbf{R}\right]}{\mathbb{P}\left[\mathrm{SB} \& x_{2} \& \mathbf{R}\right]}=\frac{\mathbb{P}[\mathrm{MB}] \mathbb{P}\left[\left(x_{2}, \mathbf{R}\right) \mid \mathrm{MB}\right]}{\mathbb{P}[\mathrm{SB}] \mathbb{P}\left[\left(x_{2}, \mathbf{R}\right) \mid \mathrm{SB}\right]}=\frac{\delta \mathbb{P}\left[\left(x_{2}, \mathbf{R}\right) \mid \mathrm{MB}\right]}{(1-\boldsymbol{\delta}) \mathbb{P}\left[\left(x_{2}, \mathbf{R}\right) \mid \mathrm{SB}\right]}
$$

Under the conjectured equilibrium strategy, the MB rejects the project when the manager is conflicted and never rejects the project when the manager is not conflicted. Thus, equation (A-3) and the state probabilities provided by Figure 1 show that

$$
\mathbb{P}\left[\mathrm{MB} \& x_{2} \& \mathbf{R}\right]=\delta \beta \frac{1}{2} .
$$

The SB, without offering discretionary compensation when the manager is not conflicted, and offering discretionary compensation when the manager is conflicted, will assure that the project is rejected if and only if it has a negative NPV. Thus, equation (A-3) and the state probabilities provided by Figure 1 show that

$$
\mathbb{P}\left[\mathrm{SB} \& x_{2} \& \mathbf{R}\right]=(1-\delta)\left(\frac{1}{8}+\frac{1}{4}(1-\theta)\right) .
$$

Inserting expressions (A-4) and (A-5) into the definition of the odds ratio, expression (A-3), yields

$$
o\left(x_{2}, \mathbf{R}\right)=\frac{\delta \beta \frac{1}{2}}{(1-\delta)\left(\frac{1}{8}+\frac{1}{4}(1-\theta)\right)}=\frac{\delta}{1-\delta} \frac{4 \beta}{3-2 \theta} .
$$

Applying the same logic we can compute the likelihood ratios for the other histories reached at $x_{2}$. These are provided below:

$$
o\left(x_{2}, \mathbf{A}^{+}\right)=\frac{\delta}{1-\delta} \frac{4(1-\beta)}{\beta(1+2 \theta)} \quad \text { and } \quad o\left(x_{2}, \mathbf{A}^{-}\right)=0 .
$$

Next note that

Because, $\theta<1$,

$$
\frac{o\left(x_{2}, \mathbf{A}^{+}\right)}{o\left(x_{2}, \mathbf{R}\right)}=\left(\frac{4}{1+2 \theta}-1\right) \frac{(1-\beta)}{\beta^{2}} .
$$

$$
\frac{4}{1+2 \theta}-1>\frac{4}{1+2}-1=\frac{1}{3} \text {. }
$$

Expression (A-8) and our assumption that $\beta<1 / 3$ imply that

$$
\frac{o\left(x_{2}, \mathbf{A}^{+}\right)}{o\left(x_{2}, \mathbf{R}\right)}=\left(\frac{4}{1+2 \theta}-1\right) \frac{(1-\beta)}{\beta^{2}}>\frac{1}{3} \frac{1-\beta}{\beta^{2}}>1 .
$$

i.e., $o\left(x_{2}, \mathbf{A}^{+}\right)>o\left(x_{2}, \mathbf{R}\right)$. Thus, the most suspicious action that the board can take after $x_{2}$ is to pay discretionary compensation, $\mathbf{A}^{+}$. By the hypothesis of the proposition, this action is outrage feasible. Thus, by Lemma $1, \mathbf{A}^{-}$and $\mathbf{R}$ are also outrage feasible. In the conjectured equilibrium the SB is implementing the shareholder optimal policy. So, clearly the SB is playing a best response. The conjectured equilibrium calls for the MB to pay discretionary compensation when the manager is not conflicted. Because paying discretionary compensation is outrage feasible and maximizes the non-conflicted manager's payoff, the candidate equilibrium strategy is a best reply when the manager is not conflicted. Now consider the MB's strategy when the manager is conflicted. The candidate equilibrium calls for the project to be rejected in this case. Because the manager is conflicted, the manager is indifferent between receiving discretionary compensation and rejecting the project. Equation (A-9) shows that paying discretionary compensation is more suspicious than rejecting the project. Given the manager's indifference when 
not conflicted, minimum suspicion requires that the $\mathrm{MB}$ reject the project. Thus, the $\mathrm{MB}$ is playing a best reply when the manager is conflicted and the equilibrium is verified.

Now consider alternative equilibria under the hypothesis that discretionary compensation is outrage feasible. By Lemma 1, this implies that all three policies are outrage feasible. Thus, the SB must follow the shareholder value maximizing policy, the same policy that the SB follows in the verified equilibrium. The MB must pay discretionary compensation to non-conflicted managers for the reasons outlined above. The only scope for an alternative equilibria is for the $\mathrm{MB}$, when the manager is conflicted, to offer discretionary compensation. However, an increase in the probability that the MB offers discretionary compensation when the manager is conflicted would increase the ratio $o\left(x_{2}, \mathbf{A}^{+}\right) / o\left(x_{2}, \mathbf{R}\right)$, i.e., make paying discretionary compensation even more suspicious. Since $o\left(x_{2}, \mathbf{A}^{+}\right) / o\left(x_{2}, \mathbf{R}\right)>1$ even in the verified equilibrium, in which the probability that the MB offers discretionary compensation to the conflicted manager is zero, in a candidate equilibrium in which the $\mathrm{MB}$ offered discretionary compensation to the manager with positive probability, it would also have to be the case that $o\left(x_{2}, \mathbf{A}^{+}\right)>o\left(x_{2}, \mathbf{R}\right)$. For the same reason, in any equilibrium (that featured a positive probability that the MB offers discretionary compensation to the conflicted manager) in which discretionary compensation is outrage feasible, it would be the case that $o\left(x_{2}, \mathbf{A}^{+}\right)>o\left(x_{2}, \mathbf{R}\right)$. However, under the hypothesis that discretionary compensation is outrage feasible, the other two histories, $\mathbf{R}$ and $\mathbf{A}^{-}$would also be outrage feasible. If the MB ensures rejection, the history $\mathbf{R}$ is always reached and this history would thus generate less suspicion while providing the manager with the same payoff. Hence, offering discretionary compensation to the conflicted manager would violate minimum suspicion. Thus, a candidate equilibrium in which the MB pays discretionary compensation when the manager is conflicted cannot exists. Hence, the verified equilibrium is unique.

Now consider the case where $x=x_{1}$. Following the same logic as above, we compute the odds ratios:

$$
o\left(x_{1}, \mathbf{R}\right)=\frac{\delta}{1-\delta} \frac{4 \beta}{1+2 \theta} \text { and } o\left(x_{1}, \mathbf{A}^{+}\right)=\frac{\delta}{1-\delta} \frac{4(1-\beta)}{\beta(3-2 \theta)} \text { and } o\left(x_{1}, \mathbf{A}^{-}\right)=0 .
$$

Using an identical argument to the $x=x_{2}$ case and the assumption that $\beta<1 / 3$ we see that

$$
o\left(x_{1}, \mathbf{A}^{+}\right) / o\left(x_{1}, \mathbf{R}\right)=\frac{1-\beta}{\beta^{2}}\left(\frac{4}{3-2 \theta}-1\right)>1 .
$$

Thus, discretionary compensation is the most suspicious history which the board can reach. An identical argument to the $x=x_{2}$ case then verifies the equilibrium and shows that it is unique.

Proof of Proposition 4. First consider public signal $x=x_{2}$. The odds ratio associated with rejecting the project is given by

$$
o\left(x_{2}, \mathbf{R}\right)=\frac{\delta\left(\frac{\beta}{2}+\alpha(1-\beta)\left(\frac{1}{8}+\frac{1-\theta}{4}\right)\right)}{(1-\delta)\left(\frac{\beta}{4}+(1-\beta)\left(\frac{1}{8}+\frac{1-\theta}{4}\right)\right)} .
$$

where we have used the fact that the SB will force acceptance in state $G$. Substituting the definition of $\alpha$ from the proposition into the right-hand side of expression (A-11) shows that $o\left(x_{2}, \mathbf{R}\right)=\delta /(1-\delta)$, the prior odds ratio. Because only two histories, $\mathbf{R}$ and $\mathbf{A}^{-}$can be 
reached under the assumption that outrage blocks paying discretionary compensation, and, at one history, the odds ratio equals the prior odds ratio, the odds ratio at the other history must also equal the prior odds ratio, i.e., $o\left(x_{2}, \mathbf{A}^{-}\right)=\delta /(1-\delta)$. Thus, the candidate equilibrium is a signal jamming equilibrium.

Next note that, under the candidate equilibrium strategy, the SB is following a shareholder efficient policy conditioned on discretionary compensation not being outrage feasible. When the manager is non-conflicted, the SB delegates investment policy to the manager, ensuring that the project is undertaken if and only if it is positive NPV. When the manager is conflicted, discretionary compensation cannot be used to extract information from the manager. Under board signal $G$, the project is expected to have positive NPV and the candidate strategy calls for the board to accept the project. Under signal $M$, the project is expected to have zero NPV and the candidate strategy calls for the project to be rejected. The MB always rejects the project when the manager is conflicted, thus maximizing the welfare of the conflicted manager, and randomizes between delegation and ensuring acceptance when the manager is not conflicted, and thus is indifferent to investment policy. Both acceptance and rejection produce the same level of suspicion, and thus these strategies by the SB and MB also satisfy the minimum suspicion criterion. Thus the equilibrium is verified.

Now consider alternative equilibria. We argue that there is no alternative equilibrium that produces a higher ex ante payoff to the shareholder. First, consider mixed-strategy equilibria. The SB will never randomize when either the manager is not conflicted, or the manager is conflicted and the board signal is $G$ or $B$. In these cases, there is a unique shareholder welfare maximizing policy - the same policy as specified in the verified equilibrium. Next note that the $\mathrm{MB}$ will never randomize when the manager is conflicted because in this case, under the assumption of the proposition that discretionary compensation is blocked, rejection is the only outcome that maximizes the manager's payoff. Finally note that any such alternative equilibria would also have to be signal jamming. This follows because suspicion across the two alternatives would have to be equated at the two histories and, because there are only two feasible histories, equating suspicion can only occur if the suspicion associated with both equals prior suspicion.

Conditional on the SB rejecting the project under signal $M, \alpha$ is the unique randomization probability that equates prior and posterior odds. Thus, the alternative outrage feasible shareholder efficient equilibria would involve randomization by the SB when the manager is conflicted and the board signal is $M$ and thus the expected NPV equals 0 . Let $\gamma$ represent the probability that the SB accepts the project in this case. Note that in the verified equilibrium $\gamma=0$. Increasing $\gamma$ would reduce the probability that the SB rejects the project. In order to maintain signal jamming, the probability that the MB rejects would also have to be lower. Thus, the MB would have to ensure acceptance with a higher probability. Since ensuring acceptance when the manager is not conflicted lowers shareholder welfare, the resulting equilibrium would not be shareholder efficient.

Now consider pure strategy equilibria. Note that a pure strategy equilibrium, in which the 
MB always delegates project selection when the manager is not conflicted, does not exist. If the MB always delegated to the non-conflicted manager, because the MB always rejects when the manager is conflicted, the MB would be rejecting the project with a higher probability than the $\mathrm{SB}$, and rejection would thus be more suspicious than acceptance. Because the non-conflicted manager is indifferent, and since rejection is more suspicious, permitting the manager to reject the project would violate the minimum suspicion condition. The other candidate pure strategy equilibrium, where the MB always forces acceptance when the manager is not-conflicted, is clearly less shareholder efficient as it involves a smaller probability of choosing the shareholder optimal action of delegation when the manager is non conflicted, and thus also cannot be a shareholder efficient democratic equilibria.

Now consider the case where the signal $x=x_{1}$. In this case, the ex ante NPV of the project is non-positive. Information about the project's NPV cannot be extracted from the manager after signal $x_{1}$ because of the shareholder outrage constraint. Thus, an optimal policy for both the $\mathrm{SB}$ and the $\mathrm{MB}$ is to reject the project when the manager is conflicted and delegate when the manager is not conflicted. If this policy is followed by both the MB and the SB, board policy will not be informative about board loyalty and thus shareholder suspicion will equal $\delta$ at both shareholder information sets, $\mathbf{A}^{-}$and $\mathbf{R}$. Thus, for both the MB and SB, the policy of rejecting the project when the manager is conflicted, and delegating when the manager is not conflicted, is an outrage feasible minimum suspicion best reply given the shareholders' conjecture that both board types will follow this policy. Thus, these policies are equilibrium policies when outrage blocks discretionary compensation. Clearly, because these polices maximize shareholder payoffs subject to the outrage constraint blocking discretionary compensation, the equilibrium is a shareholder-optimal equilibrium. Since any other policy would lower shareholder payoffs, it is the unique shareholder optimal equilibrium policy.

Proof of Proposition 5. The proof is a straightforward calculation. From the proofs of Proposition 3 we know that the suspicion associated with paying discretionary compensation for a given public signal $x$ is always higher than the suspicion associated with any other history. Thus, we need only show that the suspicion associated with paying discretionary compensation is higher under $x_{1}$ than under $x_{2}$. Using expressions (A-7) and (A-10) we see that the ratio between these two odds ratios is given by

$$
\frac{o\left(x_{1}, \mathbf{A}^{+}\right)}{o\left(x_{2}, \mathbf{A}^{+}\right)}=\frac{4}{3-2 \theta}-1
$$

Because $\theta>1 / 2$,

$$
\frac{o\left(x_{1}, \mathbf{A}^{+}\right)}{o\left(x_{2}, \mathbf{A}^{+}\right)}=\frac{4}{3-2 \theta}-1>\frac{4}{3-2 \frac{1}{2}}-1=1 .
$$

Proof of Lemma 2. In order to prove Lemma 2, we require the following technical lemma, which bounds the set of parameters that, for a given outrage constraint, can rule out discretionary compensation being blocked conditioned on the high signal, $x_{2}$. 
Lemma A.1. If

$$
\frac{\delta}{1-\delta} \frac{4(1-\beta)}{\beta(1+2 \theta)} \leq \frac{\bar{\delta}}{(1-\bar{\delta})}
$$

then no equilibrium exists in which discretionary compensation is blocked by the outrage constraint conditioned on the signal being $x_{2}$.

Proof. The proof of this lemma is tedious, but quite routine. A candidate belief is a consistent belief (Grossman and Perry (1986)) if it can constructed using Bayes rule under the assumption that probability of defection from the equilibrium for each type (i.e, state of the board, state of the firm, and state of the manager) is an outrage-feasible best reply to the candidate consistent belief. Because Bayes rule only determines conditional probabilities for events with positive probability, under a consistent belief, defection must at least be a weak best reply for one type.

A PSE requires that the belief assigned to an off-equilibrium history must be consistent, as long as a consistent belief for that history can be shown to exist.

We first show that equilibrium beliefs about the disloyalty of the board (suspicion) that exceed the outrage threshold are never consistent beliefs. Thus, for such beliefs to satisfy the conditions for a PSE, it must be the case that no consistent beliefs can be constructed for the offequilibrium history. We then show that the hypothesis of Lemma A.1 ensure that a consistent belief can be constructed. This shows that, under the hypothesis of Lemma A.1, candidate equilibria in which discretionary compensation is blocked cannot satisfy the PSE conditions.

Consider a candidate shareholder democracy equilibrium in which discretionary compensation is blocked when the signal equals $x_{2}$. The violation of the outrage constraint implies that the shareholder belief associated with $\left(x_{2}, \mathbf{A}^{+}\right), \delta^{*}\left(x_{2}, \mathbf{A}^{+}\right)$, satisfies $\delta^{*}\left(x_{2}, \mathbf{A}^{+}\right)>\bar{\delta}$. The outrage constraint thus implies that $\left(x_{2}, \mathbf{A}^{+}\right)$is off the equilibrium path. This belief is not consistent in the sense of Grossman and Perry (1986) when defining a PSE: Because of the outrage constraint, under this belief, the set of types that would weakly gain from defecting to offering discretionary compensation is empty. Thus, the belief $\delta^{*}\left(x_{2}, \mathbf{A}^{+}\right)$will satisfy the PSE conditions if and only if no consistent belief can be assigned to $\left(x_{2}, \mathbf{A}^{+}\right)$.

We will now construct a consistent belief that can be assigned to $\left(x_{2}, \mathbf{A}^{+}\right)$. This requires comparing the payoffs to the board in the candidate equilibrium with the board's payoff under a candidate consistent belief. As consistency requires that there is a positive probability that the board will defect given the candidate consistent beliefs, the candidate consistent belief, if it is a consistent belief, must not violate the outrage constraint at the off-equilibrium history $\left(x_{2}, \mathbf{A}^{+}\right)$.

We first consider board payoffs in the candidate equilibrium. In this equilibrium, discretionary compensation is blocked by the outrage constraint. Thus, there is a unique feasible action that maximizes the manager's payoff when the manager is conflicted-rejecting the project. Hence, in the candidate equilibrium, the MB will reject the project when the manager is conflicted. When the manager is not conflicted, since paying discretionary compensation is blocked, the MB will choose the action that minimizes suspicion. For this reason, it cannot be the case that the MB, when the manager is not conflicted, is rejecting the project with probability 1 . If that were the case, the project would only be accepted by the SB, and suspicion would 
thus be minimized by accepting the project.

Thus, in the candidate equilibrium, when the manager is not conflicted, the MB is either indifferent between accepting the project and rejecting the project, or the MB strictly prefers to accept the project. In the first case, we call the equilibrium a "signal-jamming equilibrium", while in the second case, we call the equilibrium a "non signal-jamming equilibrium". In signal jamming equilibria, for reasons discussed in the proof of Proposition 4, the equilibrium assigns the prior level of suspicion to both of the two on-the-equilibrium path histories, $\left(x_{2}, \mathbf{A}^{-}\right)$and $\left(x_{2}, \mathbf{R}\right)$.

In non-signal jamming equilibria, when the manager is not conflicted, the MB will never reject the project. We need to compute an upper bound on the suspicion in such equilibria associated with rejection. To make this calculation, note that suspicion is maximized by minimizing the probability that the SB rejects, i.e, maximizing the probability that the SB accepts. Shareholder welfare considerations ensure that the SB cannot accept the project when the manager is not conflicted and project is negative NPV. Because the state is $G$ or $M$ when signal $x_{2}$ is realized, and, in these states, the expected NPV of the project is non-negative, the SB can accept the project in these states when the manager is conflicted and discretionary compensation is blocked. Thus, an upper bound on the level of suspicion is provided by the Bayes computation of the level of suspicion generated by the SB rejecting the project only when the manager is not conflicted and project NPV being negative. We call this upper bound $\delta_{+}$and call the corresponding odds ratio $o_{+}$. Computing the odds ratio produces

$$
o_{+}=\frac{\delta}{1-\delta} \frac{\frac{1}{2} \beta}{\left(\frac{1}{4}(1-\beta)(1-\theta)+\frac{1}{4}(1-\beta)\left(1-\frac{1}{2}\right)\right)}=\frac{\delta}{1-\delta} \frac{4 \beta}{(1-\beta)(3-2 \theta)} .
$$

These observation imply the following result:

\section{Result 1}

Suspicion in any equilibrium in which discretionary compensation is blocked satisfies the following conditions:

(a) If the equilibrium is signal jamming, $o^{*}\left(x_{2}, \mathbf{R}\right)=o^{*}\left(x_{2}, \mathbf{A}^{-}\right)=\delta /(1-\delta)$,

(b) If the equilibrium is not signal jamming, $o^{*}\left(x_{2}, \mathbf{R}\right) \leq o_{+}$.

Now consider the following family of defection strategies indexed by $\sigma \in[0,1]$ : (a) MB: if the manager is not conflicted, defect to offering discretionary compensation. (b) SB: defect to offering discretionary compensation if and only if the manager is conflicted. (c) MB: if the manager is conflicted, defect to paying discretionary compensation with probability $\sigma \in[0,1]$. Based on manager (shareholder) welfare optimization, strategies (a) and (b) are always best responses provided the candidate consistent belief does not exceed the outrage threshold. (c) is a best reply provided that $\sigma=0$ whenever equilibrium suspicion is less than the candidate consistent belief, and $\sigma=1$ whenever equilibrium suspicion is greater than the candidate consistent belief.

We call the odds that the manager is conflicted, produced by applying Bayes rule to defection strategy $\sigma, o_{d}(\sigma)$. Note that defection strategy $\sigma=0$ corresponds to the case where the 
signal is $x_{2}$, the MB offers discretionary compensation if and only if the manager is not conflicted, and the SB offers discretionary compensation if and only if the manager is conflicted. A calculation of the odds ratio in this case was provided by equation (A-7). Using this equation, we see that

$$
o_{d}(0)=\frac{\delta}{1-\delta} \frac{4(1-\beta)}{\beta(1+2 \theta)} .
$$

Next, we compute $o_{d}(1)$. These odds are generated by the $\sigma=1$ defection strategy, the strategy under which the MB always defects. The odds ratio for this strategy implied by Bayes rule is given by

$$
o_{d}(1)=\frac{\delta \times \frac{1}{2}}{(1-\delta) \times \frac{1}{2} \times \beta \times \theta}=\frac{\delta}{1-\delta} \frac{1}{\beta \theta} .
$$

Next, note that under our parameter restrictions,

$$
o_{d}(1)=\frac{\delta}{1-\delta} \frac{1}{\beta \theta}>o_{+}=\frac{\delta}{1-\delta} \frac{4 \beta}{(1-\beta)(3-2 \theta)} .
$$

Inequality (A-16) can be verified by noting that $o_{d}(1)-o_{+}$is decreasing in both $\theta$ and $\beta$ and evaluated at the highest permitted values of these parameters, $\beta=1 / 3$ and $\theta=1, o_{d}(1)-o_{+}=$ $\delta /(1-\delta)>0$.

We now exhibit a consistent belief for $\left(x_{2}, \mathbf{A}^{+}\right)$. Constructing this belief requires us to show that there exists a candidate consistent belief and $\sigma \in[0,1]$ such that the $\sigma$-defection strategy is an outrage feasible best response to the candidate consistent belief and the candidate consistent belief equals the posterior level of suspicion produced by applying Bayes rule to the $\sigma$-defection strategy. Managerial welfare is unaffected by defection when the manager is conflicted. So, in this case, the MB's defection decision is determined by reputational considerations alone, i.e., the level of suspicion associated with the defection strategy in comparison to the candidate equilibrium strategy. In contrast, when (a) the board is SB or (b) the board is MB and the manager is not conflicted, board best responses are only affected by the outrage threshold and considerations of shareholder (manager) welfare. Thus, the defection decision is only sensitive to the candidate consistent belief, provided this belief does not exceed the outrage threshold, when the manager is conflicted and the board is MB. This implies that the key to establishing belief consistency is verifying that, under the candidate consistent belief, the probability that the MB defects, when the manager is conflicted, assigned by the $\sigma$-defection strategy is a best response and produces the candidate consistent belief.

Next note that in the candidate equilibrium, in which discretionary compensation is blocked, the unique optimal action for the MB when the manager is conflicted is to reject the project. Thus, the MB's defection decision will be based on a comparison of the suspicion associated with rejecting the project in the candidate equilibrium and the suspicion associated with paying discretionary compensation to the manager under the candidate consistent belief. We have two cases to consider.

Case 1: suppose that either (1.a) the candidate equilibrium is a signal jamming equilibrium or that (1.b) the candidate equilibrium is not a signal jamming equilibrium but $o^{*}\left(x_{2}, \mathbf{R}\right) \leq o_{d}(0)$. Let the candidate consistent belief assignment be $\hat{\delta}_{d}\left(x_{2}, \mathbf{A}^{+}\right)=o_{d}(0) /\left(1+o_{d}(0)\right)$. In case 
1.a, Result 1.a, implies that $o^{*}\left(x_{2}, \mathbf{R}\right)=\delta /(1-\delta)$. Inspection of equation (A-14) shows that $o_{d}(0)>\delta /(1-\delta)$, thus Result 1.a implies that $o^{*}\left(x_{2}, \mathbf{R}\right)<o_{d}(0)$. In case 1.b, $o^{*}\left(x_{2}, \mathbf{R}\right) \leq o_{d}(0)$ by assumption. Thus, in both cases, under the candidate consistent belief, defections which lead to $\left(x_{2}, \mathbf{A}^{+}\right)$produce a weakly higher level of suspicion than the unique optimal action in the candidate equilibrium for the MB when the manager is conflicted-reject the project. The hypothesis of the Lemma A.1 and equation (A-14) show that the suspicion associated with $o_{d}(0)$ is not sufficient to violate the outrage constraint. Thus, the conditions for the defection strategy $\sigma=0$ being a best response to the candidate consistent belief, $\hat{\delta}_{d}\left(x_{2}, \mathbf{A}^{+}\right)$, are satisfied. The posterior suspicion generated by this defection strategy under Bayes rule equals $\hat{\delta}_{d}\left(x_{2}, \mathbf{A}^{+}\right)$ by construction. Thus, the candidate consistent belief is consistent.

Case 2: suppose that $o^{*}\left(x_{2}, \mathbf{R}\right)>o_{d}(0)$ and the equilibrium is not signal-jamming. In this case, as shown by Result 1.b and inequality (A-16), $o^{*}\left(x_{2}, \mathbf{R}\right) \leq o_{+}<o_{d}(1)$. Hence, $o_{d}(0)<$ $o^{*}\left(x_{2}, \mathbf{R}\right)<o_{d}(1)$. Because, $\sigma \hookrightarrow o_{d}(\sigma)$ is continuous, from the intermediate value theorem it follows that there exists $\sigma^{o} \in(0,1)$ such that $o_{d}\left(\sigma^{o}\right)=o^{*}\left(x_{2}, \mathbf{R}\right)$. Let the candidate consistent belief assignment be $\hat{\delta}_{d}\left(x_{2}, \mathbf{A}^{+}\right)=o_{d}\left(\sigma^{o}\right) /\left(1+o_{d}\left(\sigma^{o}\right)\right)$. Because $o_{d}\left(\sigma^{o}\right)=o^{*}\left(x_{2}, \mathbf{R}\right)$, $\hat{\delta}_{d}\left(x_{2}, \mathbf{A}^{+}\right)=\delta^{*}\left(x_{2}, \mathbf{R}\right)$ and because the history of rejecting the project is reached in the candidate equilibrium, $\delta^{*}\left(x_{2}, \mathbf{R}\right)$ does not violate the outrage constraint. Because $\hat{\delta}_{d}\left(x_{2}, \mathbf{A}^{+}\right)=$ $\delta^{*}\left(x_{2}, \mathbf{R}\right), \hat{\delta}_{d}\left(x_{2}, \mathbf{A}^{+}\right)$does not violate the outrage constraint either. Thus, the suspicion associated with rejecting the project in the candidate equilibrium equals the suspicion associated with defection. Since, the MB's unique optimal action in the candidate equilibrium when the manager is conflicted is to reject the project, and since defection has no effect on the manager's payoff, when the manager is conflicted the MB is indifferent to defection. Thus, the conditions for the defection strategy $\sigma=\sigma^{o}$ being a best response to the candidate consistent belief, $\hat{\boldsymbol{\delta}}_{d}\left(x_{2}, \mathbf{A}^{+}\right)$are satisfied. The posterior suspicion generated by this defection strategy under Bayes rule equals $\hat{\delta}_{d}\left(x_{2}, \mathbf{A}^{+}\right)$by construction. Thus, the candidate consistent belief is consistent.

Given Lemma A.1, the proof of Lemma 2 is straightforward: As noted in the proof of Lemma A.1, the hypothesis of the lemma is equivalent to $o\left(x_{2}, \mathbf{A}^{+}\right) \leq \bar{\delta} /(1-\overline{\boldsymbol{\delta}})$, where $o\left(x_{2}, \mathbf{A}^{+}\right)$ is the odds ratio associated with paying discretionary compensation under signal $x_{2}$ when discretionary compensation is not blocked by outrage. ${ }^{16}$ When discretionary compensation is not blocked after signal $x_{1}$, the odds ratio for the board being disloyal must not produce a violation of the outrage constraint, i.e, $o\left(x_{1}, \mathbf{A}^{+}\right) \leq \bar{\delta} /(1-\bar{\delta}) .{ }^{17}$ Proposition 5 shows that $o\left(x_{2}, \mathbf{A}^{+}\right)<o\left(x_{1}, \mathbf{A}^{+}\right)$. Thus, if $o\left(x_{1}, \mathbf{A}^{+}\right) \leq \bar{\delta} /(1-\bar{\delta}), o\left(x_{2}, \mathbf{A}^{+}\right) \leq \bar{\delta} /(1-\bar{\delta})$. This implies that the hypothesis of Lemma A.1 is verified. Hence, discretionary compensation not blocked in any equilibrium after signal $x_{2}$.

Proof of Proposition 6. Our proof of Proposition 6 faces one obstacle-the parameter space is constrained by the non-linear constraint provided by inequality (1). To surmount this obstacle

\footnotetext{
${ }^{16}$ See equation (A-7) in the proof of Proposition 3 for the definition of $o\left(x_{2}, \mathbf{A}^{+}\right)$.

${ }^{17}$ See equation (A-10) in the proof of Proposition 4 for the definition of $o\left(x_{1}, \mathbf{A}^{+}\right)$
} 
we reparameterize the model using the following 1-1 transformation of $(\theta, P)$ into two new variables, $r$ and $\zeta$, defined by

$$
r=\frac{1-\theta}{\theta}, \quad \zeta=P \frac{\theta}{1-\theta}
$$

Note that this map $(\theta, P) \hookrightarrow(r, \zeta)$ maps all parameter choices for $(\theta, P)$ which satisfy condition (1) as well as the conditions that $P>0$ and $\theta \in\left(\frac{1}{2}, 1\right) 1-1$ onto the unit square, $(0,1)^{2}$. Because assumption (1) places no restriction on the other parameters, reparameterization represents the admissible parameter space as a hypercube. We will use this parameterization in parts of the proof where it helps with the derivations.

In addition to the reparameterization, the proof of Proposition 6 requires the following technical lemma.

Lemma A.2. The set of shareholder prior assessments under which shareholder democracy dominates the two ex ante policies, $C R$ and FD is an interior interval of $[0,1]$ defined as follows:

$$
\left\{\delta \in[0,1]: u_{S h}^{D}-u_{S h}^{C R} \geq 0 \& u_{S h}^{D}-u_{S h}^{F D} \geq 0\right\}= \begin{cases}{\left[\delta^{-}, \delta^{+}\right]} & \text {if } 0<\delta^{-} \leq \delta^{+}<1 \\ \varnothing & \text { otherwise }\end{cases}
$$

where

$$
\begin{aligned}
& \delta^{-}=\beta\left(\frac{(1-P)(3-2 \theta)}{4(1-2 \beta+P)-((1-\beta)-\beta(1-P))(3-2 \theta)}\right), \\
& \delta^{+}=\beta\left(1-\frac{(8-(3-2 \theta)) P(1-\beta)}{(3-2 \theta)(1+P \beta)+4 P(1-2 \beta)}\right) .
\end{aligned}
$$

Proof. Note the probability that the board is MB equals $\delta$. The ex ante payoff to shareholders under democracy, $u^{D}$, is the weighted average of their ex ante payoffs under an MB and an SB. Taking expectations over the signal contingent payoffs under democracy provided by Table 4 we can determine the ex ante payoff from democracy for each board type:

$$
\begin{aligned}
u_{\mathrm{Sh}}^{\mathrm{D}} & =\delta u_{\mathrm{Sh}: \mathrm{MB}}^{\mathrm{D}}+(1-\delta) u_{\mathrm{Sh}: \mathrm{SB}}^{\mathrm{D}}, \quad \text { where } \\
u_{\mathrm{Sh}: \mathrm{MB}}^{\mathrm{D}} & =\frac{1}{8}(1-\beta)(1+2 \theta-4 P), \\
u_{\mathrm{Sh}: \mathrm{SB}}^{\mathrm{D}} & =\frac{1}{8}(4(1-\beta)+\beta((1-P)(2 \theta+1))) .
\end{aligned}
$$

The comparable expressions for ex ante payoffs under FD and CR are provided in Section 2.4. Computing the difference between shareholder payoffs under democracy and under the two ex 
ante policies yields

$$
\begin{aligned}
u_{\mathrm{Sh}}^{\mathrm{D}}-u_{\mathrm{Sh}}^{\mathrm{CR}}= & \delta \overbrace{\left(-\frac{1}{8}((1-\beta)(3-2 \theta+4 P))\right.}^{A_{\mathrm{CR}}}+ \\
& (1-\delta) \overbrace{\left(\frac{1}{8} \beta(3-P(1+2 \theta)-2 \theta)\right)}^{B_{\mathrm{CR}}}, \\
u_{\mathrm{Sh}}^{\mathrm{D}}-u_{\mathrm{Sh}}^{\mathrm{FD}}= & \overbrace{\left(\frac{1}{8}(2 \overbrace{(1-3 \beta)+4 P+(1-\beta)(2 \theta-1))}^{A_{\mathrm{FD}}})\right.}^{B_{\left(-\frac{1}{8}(1-P) \beta(3-2 \theta)\right)}^{B_{\mathrm{FD}}}} .
\end{aligned}
$$

We see that these difference functions are affine in $\delta$; thus the set of values of $\delta \in[0,1]$ that satisfy both $u_{\mathrm{Sh}}^{\mathrm{D}}-u_{\mathrm{Sh}}^{\mathrm{CR}} \geq 0$ and ${ }_{\mathrm{Sh}}^{\mathrm{D}}-u_{\mathrm{Sh}}^{\mathrm{FD}} \geq 0$ is the intersection of two convex subsets of $[0,1]$. Thus the set is either empty or an interval. $A_{\mathrm{CR}}<0$ and this subset cannot contain 1 and $B_{\mathrm{FD}}<0$ so the subset cannot contain 0 . Explicitly computing the endpoints of this interval provides expressions (A-18) and (A-19).

First note that part (a) follows from the argument given in the text following the Proposition. Next note that part (b) follows simply from expression (A-19), which implies that $\delta^{+}<\beta$. Because democratic governance is never optimal for $\delta>\delta^{+}$, part (b) follows. Now consider part (c). Under the reparameterization defined by equation (A-17) we can write the lower and upper limits of the region were democracy is optimal as follows:

$$
\begin{aligned}
& d^{-}=\frac{(1+3 r) \beta(1-r \zeta)}{3-6 \beta+r^{2}(4-3 \beta) \zeta+r(1-2 \beta+(4-\beta) \zeta)}, \\
& d^{+}=\frac{\beta\left(1+3 r(1-\zeta)-r^{2} \zeta\right)}{1+3 r+r(4+r(4-5 \beta)-7 \beta) \zeta} .
\end{aligned}
$$

Under our parametric assumptions, the numerators and denominators of these expressions are positive. Also note that,

$$
\text { Numerator }\left[d^{-}\right]-\text {Numerator }\left[d^{+}\right]=2(1-r) r \beta \zeta>0 .
$$

The range of prior probabilities over which democracy is optimal is empty if $d^{+}<d^{-}$. Expression (A-25) shows that the numerator of $d^{-}$is always greater than the numerator of $d^{+}$. Thus, a sufficient condition for $d^{+}<d^{-}$is that the denominator of $d^{-}$be smaller than the denominator of $d^{+}$. Next, note that

Denominator $\left[d^{-}\right]-$Denominator $\left[d^{+}\right]$

$$
=2(((1-r)-\beta(3+r))+2 \zeta r \beta(r-3) .
$$

The second term is clearly negative, and the first one is negative if $\frac{3+r}{1-r}>\frac{1}{\beta}$, which is equivalent to $\theta-\frac{1}{2}<\frac{\beta}{1-\beta}$. The expression in the Proposition is just the translation back to the $(\beta, \theta)$ parameterization. 